\title{
How has our knowledge of dinosaur diversity through geologic time changed through research history?
}

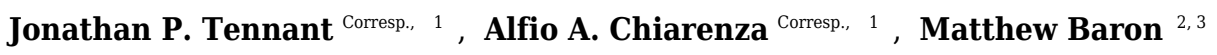 \\ 1 Department of Earth Science and Engineering, Imperial College London, London, United Kingdom \\ 2 Department of Earth Science, University of Cambridge, Cambridge, United Kingdom \\ 3 Earth Sciences Department, Natural History Museum, London, United Kingdom \\ Corresponding Authors: Jonathan P. Tennant, Alfio A. Chiarenza \\ Email address: jon.tennant.2@gmail.com, a.chiarenza15@imperial.ac.uk
}

Assessments of dinosaur macroevolution at any given time can be biased by the historical publication record. Recent studies have analysed patterns in dinosaur diversity that are based on secular variations in the numbers of published taxa. Many of these have employed a range of approaches that account for changes in the shape of the taxonomic abundance curve, which are largely dependent on databases compiled from the primary published literature. However, how these 'corrected' diversity patterns are influenced by the history of publication remains largely unknown. Here, we investigate the influence of publication history between 1991 and 2015 on our understanding of dinosaur evolution using raw diversity estimates and Shareholder Quorum Subsampling for the three major subgroups: Ornithischia, Sauropodomorpha and Theropoda. We find that, while sampling generally improves through time, there remain periods and regions in dinosaur evolutionary history where diversity estimates are highly volatile (e.g., the latest Jurassic of Europe, the mid-Cretaceous of North America, and the Late Cretaceous of South America). Our results show that historical changes in database compilation can often substantially influence our interpretations of dinosaur diversity. 'Global' estimates of diversity based on the fossil record are often also based on incomplete, and distinct regional signals, each subject to their own sampling history. Changes in the record of taxon abundance distribution, either through discovery of new taxa or addition of existing taxa to improve sampling evenness, are important in improving the reliability of our interpretations of dinosaur diversity. Furthermore, the number of occurrences and newly identified dinosaurs is still rapidly increasing through time, suggesting that it is entirely possible for much of what we know about dinosaurs at the present to change within the next 20 years. 
1 How has our knowledge of dinosaur diversity through geologic time changed through research history?

2 Jonathan P. Tennant ${ }^{1 *}$, Alfio Alessandro Chiarenza ${ }^{1}$, Matthew Baron ${ }^{2,3}$

$3{ }^{1}$ Department of Earth Science and Engineering, Imperial College London, London, SW6 2AZ, United

4 Kingdom.

5 2Department of Earth Science, University of Cambridge, Cambridge, CB2 3EQ, United Kingdom

$6 \quad{ }^{3}$ Earth Sciences Department, Natural History Museum, London, SW7 5BD, United Kingdom

$7 \quad$ *Corresponding author: jon.tennant.2@gmail.com

\section{Abstract}

Assessments of dinosaur macroevolution at any given time can be biased by the historical publication record. Recent studies have analysed patterns in dinosaur diversity that are based on secular variations in the numbers of published taxa. Many of these have employed a range of approaches that account for changes in the shape of the taxonomic abundance curve, which are largely dependent on databases compiled from the primary published literature. However, how these 'corrected' diversity patterns are influenced by the history of publication remains largely unknown. Here, we investigate the influence of publication history between 1991 and 2015 on our understanding of dinosaur evolution using raw diversity estimates and Shareholder Quorum Subsampling for the three major subgroups: Ornithischia, Sauropodomorpha and Theropoda. We find that, while sampling generally improves through time, there remain periods and regions in dinosaur evolutionary history where diversity estimates are highly volatile (e.g., the latest Jurassic of Europe, the mid-Cretaceous of North America, and the Late Cretaceous of South America). Our results show that historical changes in database compilation can often substantially influence our interpretations of dinosaur diversity. 'Global' estimates of diversity based on the fossil record are often also based on incomplete, and distinct regional signals, each subject to their own sampling history Changes in the record of taxon abundance distribution, either through discovery of new taxa or addition of existing taxa to improve sampling evenness, are important in improving the reliability of our interpretations of dinosaur diversity. Furthermore, the number of occurrences and newly identified dinosaurs is still rapidly increasing through time, suggesting that it is entirely possible for much of what we know about dinosaurs at the present to change within the next 20 years. 
In the latter half of the $20^{\text {th }}$ Century, palaeobiology underwent a renaissance by adopting a more quantitative analytical approach to understanding changes in the fossil record through time (Valentine \& Moores 1970; Raup 1972; Gould \& Eldredge 1977; Sepkoski et al. 1981; Van Valen 1984; Sepkoski Jr 1996). This research was largely focussed around estimating patterns of animal diversity, extinction and speciation through time, and what the external processes governing these were. To this day, reconstructing the diversity of life through geological time remains one of the most crucial aspects of palaeobiology, as it allows us to address broader questions about the evolution of life and what the mechanisms of extinction and recovery are. These pioneering analyses were largely based on an archive of range-through taxa of marine animals, known as the 'Sepkoski Compendium'. More recently, analytical palaeobiology has had a second wave of innovation, in part due to development of large databases that catalogue fossil occurrences and associated data such as the Paleobiology Database (www.paleobiodb.org), and also due to development of increasingly sophisticated analytical subsampling (Alroy 2000b; Alroy 2003; Alroy 2010a; Starrfelt \& Liow 2016) and modelling (Smith \& McGowan 2007; Lloyd 2012) techniques. Together, these are helping to provide new insight into how we can use the fossil record to understand the large-scale evolutionary patterns and processes that have shaped the history of life.

All of these studies, both older and more recent, are under-pinned by a single principle, in that they rely on the recorded number of identifiable fossiliferous occurrences present through geological time. Despite meticulous work to ensure that these databases and compendia represent the best possible records of historical trends, there has been continuous discussion as to the accuracy of the data, and the extent to which estimates of palaeodiversity might be confounded by such bias. These biases include factors such as heterogeneous sampling intensity, fossiliferous rock availability, and variable depth of taxonomic research (Raup 1972; Raup 1976; Uhen \& Pyenson 2007; Benton 2008a; Benton 2008b; Marx \& Uhen 2010; Tarver et al. 2011; Smith et al. 2012; Smith \& Benson 2013). compilation history through changes in taxonomy, stratigraphic resolution, and sampling influences the shape of macroevolutionary patterns (Sepkoski Jr 1993).Based on comparison of the two compendia built in 1982 and 1992, Sepkoski (1993) found that in spite of numerous taxonomic changes over ten 
years, the overall patterns of diversity for marine animals remained relatively constant, with the main notable change being that overall diversity was consistently higher in the 1992 compilation. Alroy (2000a) similarly showed that database age does appear to have an influence on North American mammal diversity estimates, and Alroy (2010c) further demonstrated that diversity estimates based on data from the Paleobiology Database were proportionally similar to either the genus- or family-level results based on Sepkoski's original compendium. At the present, there are three main arguments regarding the historical reliability of diversity curves (e.g., Sepkoski et al. (1981); Sepkoski Jr (1993); Alroy (2000a)): firstly that because independent datasets produce similar diversity curves, this suggests that convergence on a common signal reflecting either a real evolutionary, fossil record structure, or taxonomic phenomenon; second, that the addition of new data to existing compilations should yield only minor changes to resulting diversity estimates; and third, that the addition of new data can potentially dramatically alter the shape of diversity (counter to the first and second arguments). At the present, the first argument appears to be the best supported by analytical evidence (Sepkoski 1993; Alroy 2000c).

However, besides Sepkoski and Alroy's work, relatively little consideration has been given to how publication or database history can influence macroevolutionary patterns, despite an enormous reliance on their research utility (although see Benton (2008a); Benton (2008b); Tarver et al. (2011) for examples using vertebrates). In particular, to our knowledge, no one has yet tested this potential influence using an occurrence-based tetrapod dataset, such as those available from the Paleobiology Database. This is important, given that a wealth of recent studies, and in particular on tetrapod groups, have focussed on estimating diversity patterns through geological time and interpreting what the potential drivers of these large-scale evolutionary patterns might be (Butler et al. 2009; Benson \& Butler 2011; Butler et al. 2011; Mannion et al. 2015; Nicholson et al. 2015; Benson et al. 2016; Grossnickle \& Newham 2016; Nicholson et al. 2016; Tennant et al. 2016a; Brocklehurst et al. 2017). Many of these studies have employed subsampling methods that are sensitive to changes in the shape of the taxonomic abundance distribution, which we would expect to change in a non-random fashion based on new fossil discoveries through time as they are published (Benton et al. 2011; Benton et al. 2013a; Benton 2015) (e.g., due to the opening up of new discovery regions for geopolitical reasons, or the historical and macrostratigraphic availability of fossil-bearing rock formations). Furthermore as sampling increases through time we might also expect the relative proportion of singleton occurrences to decrease, improving the evenness of the underlying sampling pool (Alroy 2010a; Chao \& Jost 2012), and therefore influencing calculated diversity estimates (see Methods below). Assessing this influence in a historical 
91 context is therefore important for understanding how stable our interpretations of evolutionary 92 patterns are.

93 While the data used in these analyses are typically based on a 'mature' dataset that has undergone 94 rigorous taxonomic scrutiny and data addition or refinement, they often tend to neglect explicit 95 consideration of the potential influence of temporal variations in the publication record (which these 96 databases are explicitly based on). This has important implications for several reasons. First we might expect the shape of both raw and subsampled diversity curves to change through time in concert with new discoveries and as sampling increases (Sepkoski Jr 1993; Alroy 2000a), or that subsampled diversity estimates stabilise at some point. Second, this could therefore impact our interpretations of the relative magnitude, tempo and mode of apparent radiations and extinctions Third, if the shape of estimated diversity curves change (either based on raw or 'corrected' data), we could see that the strength of results from comparisons of diversity with extrinsic factors such as sea-level or palaeotemperature (Benson et al. 2010; Benson \& Butler 2011; Butler et al. 2011; Peters \& Heim 2011b; Mayhew et al. 2012; Martin et al. 2014; Mannion et al. 2015; Nicholson et al. 2015; Tennant et al. 2016a; Tennant et al. 2016b) will change.

106

As our data become updated, capturing this influence of sampling variation becomes more important through longer periods of time. We might expect sampling error to be highest earlier on in sampling history, and to reduce through time, therefore improving the reliability of our correlation estimates. However, if our subsampled diversity estimates remain stable through historical time, then we can be more confident in these interpretations, as well as the effectiveness of subsampling methods in reliably estimating diversity. Recently, this potential issue highlighted by Jouve et al. (2017) in a small study of Jurassic and Cretaceous thalattosuchian crocodylomorphs. Those authors tested the conclusions of Martin et al. (2014) and their assertion that sea-surface temperature was the primary factor driving marine crocodylomorph evolution, contra Mannion et al. (2015) and Tennant et al. (2016a). They found that the strength of the relationships reported by the first study, also different to those reported by (Mannion et al. 2015) and (Tennant et al. 2016a), were fairly unstable even based on very recent changes in taxonomy. This taxonomically constrained example provides an interesting case of how small changes in publication history can lead to potentially different or conflicting interpretations of macroevolutionary patterns.

In this study, we investigate the influence of publication history on our reading and understanding of diversity patterns through time. For this, we use the clade Dinosauria (excluding Aves) as a study group, 
122 as they have an intensely sampled fossil record and a rich history of taxonomic and macroevolutionary

123 research. We note that this is just one of a whole suite of potential biases in palaeodiversity studies (e.g., 124 appropriate time-binning methods, optimal analytical protocols, or the impact of variation in the rock 125 record through space and time), and these factors are discussed in more detail elsewhere (Peters \& 126 Heim 2010; Benson \& Butler 2011; Heim \& Peters 2011; Peters \& Heim 2011b; Benson \& Upchurch 2013; 127 Benton et al. 2013b; Dunhill et al. 2014; Benton 2015; Benson et al. 2016; Tennant et al. 2016b).

Material and Methods

Dinosaur occurrences dataset

131 We used a primary dataset of dinosaur body fossil occurrences drawn from the Paleobiology Database 132 (November, 2017) that spans the entirety of the Late Triassic to end-Cretaceous (66-235 Ma) (SI 1). 133 These data are based on a comprehensive compilation effort from multiple workers, and represent updated information on modern dinosaur taxonomy and palaeontology at this time. The records comprised only body fossil remains, and excluded ootaxa and ichnotaxa. This dataset was divided into the three major clades, Sauropodomorpha, Ornithischia, and Theropoda. We excluded Aves as they have a fossil record dominated by different and often exceptional modes of preservation. Having limited occurrences of exceptionally preserved fossils will bias our results, particularly in time periods characterised by the presence of avian-bearing Konservat-Lagerstätten (Brocklehurst et al. 2012; Dean et al. 2016). We elected to use genera, as these are more readily identified and diagnosed, which means that we can integrate occurrences that are resolved only to the genus level (e.g., Allosaurus sp.), and therefore include a substantial volume of data that would be lost at any finer resolution (Robeck et al. 2000). A potential issue with a genus-level approach is that analysing palaeodiversity at different taxonomic levels can potentially lead to different interpretations about what the external factors mediating it are (Wiese et al. 2016). Despite the fact that some dinosaur genera are multispecific, it has been shown previously that both genus- and species-level dinosaur diversity curves are very similar

147 (Barrett et al. 2009), and that there is more error in species level dinosaur taxonomy than for genera 148 (Benton 2008b). It has also been repeatedly demonstrated that the shape of species and genus curves are strongly correlated in spite of differential taxonomic treatment (Alroy 2000a; Butler et al. 2011; Mannion et al. 2015), and therefore a genus level compilation should be sufficient for the scope of the 
153 binning approach (Mannion et al. 2015; Benson et al. 2016), but this has limitations in that it reduces the 154 number of data points for statistical analyses, and can artificially group fossil occurrences from different 155 stages that never temporally co-existed (Gibert \& Escarguel 2017), which would confound our analyses. 156 Only body fossil occurrences that could be unambiguously assigned to a single stage bin were included, 157 and those in which assignment to a single stage bin was either ambiguous or not possible were excluded. 158 This procedure was implemented in order to avoid the over-counting of taxa or occurrences that have poorly constrained temporal durations or are contained within multiple time bins. Each dinosaurian subgroup was further sub-divided into approximately contiguous palaeocontinental regions: Africa, Asia, Europe, South America, and North America (Mannion et al. 2015). Unfortunately, sampling is too poor to analyse patterns in Antarctica, Australasia, or Indo-Madagascar, although these regions remain included in the global analyses. We also provide data on the number of newly identified occurrences (SI 2) and newly named genera (SI 3) based on publication date, as well as a list of dinosaur taxa that became invalidated between 1991 and 2015 (SI 1).

To test how diversity changes through time, we reduced the primary dataset by successively deleting data from publications of each individual occurrence recursively at two year intervals. Note that these dates are not the same as the date that the actual entries were made into the database, but the explicit date of publication of that occurrence record in the published version of record. We stopped at 1991, giving 12 sequential temporal datasets for each dinosaurian clade. What each version represents is the maturity of the dataset with respect to its present state (and taxonomy as of 2015) based on publication history. Two methods were used to assess diversity patterns. Firstly, empirical diversity based on raw inbin counts of taxa. This method has been strongly suggested to be a 'biased' or poor estimator of true diversity as it is influenced by heterogeneous sampling (Benson et al. 2010; Benson \& Butler 2011; Benson \& Upchurch 2013; Butler et al. 2013; Smith \& Benson 2013; Newham et al. 2014; Mannion et al. 2015; Tennant et al. 2016b). Secondl we employed the shareholder quorum subsampling (SQS) method, which was designed to account for differences in the shape of the taxon-abundance curve (Alroy 2010c; Alroy 2010a), and implemented in Perl (SI 4, 5).

SQS standardizes taxonomic occurrence lists based on an estimate of coverage to determine the relative magnitude of taxonomic biodiversity trends (Alroy 2010c; Alroy 2010a). In this method, each taxon within a sample pool (time bin) is treated as a 'shareholder', whose 'share' is its relative occurrence 
184 frequency. Taxa are randomly drawn from compiled in-bin occurrence lists, and when a summed 185 proportion of these 'shares' reaches a certain 'quorum', subsampling stops and the number of sampled 186 taxa is summed. Coverage, as a measure of sampling quality, is defined as the proportion of the 187 frequency distribution of taxa within a sample. It is estimated by using randomized subsampling to 188 calculate the mean value of Good's $u$, which is defined as 1 minus the number of singleton occurrences, 189 divided by the total number of occurrences (Good 1953). A coverage value of zero indicates that all taxa 190 are singleton occurrences (i.e., that all occurrences of a taxon are restricted to a single collection within 191 a time bin). Higher coverage values indicate more even sampling of taxa, and therefore provides a 192 measure of sample completeness that is independent of the overall sample pool size. For each time bin, $193 u$ is then divided into the quorum level (Alroy 2010a), thereby providing an estimate of the coverage of 194 the total occurrence pool. In all subsampling replicates, singletons were excluded to calculate diversity 195 (but included to calculate Good's u), as they can distort estimates of diversity. Dominant taxa (those 196 with the highest frequency of occurrences per bin) were included, and where these taxa are drawn, 1 is 197 added to the subsampled diversity estimate for that bin (Alroy 2010c). Finally, single large collections 198 that can create the artificial appearance of poor coverage were accounted for by counting occurrences of taxa that only occur in single publications, as opposed to those which occur in single collections, and excluding taxa that are only ever found in the most diverse collection. 1000 subsampling trials were run for each dataset (Theropoda, Ornithischia, and Sauropodomorpha, for each region and 2 year time interval), and the mean diversity was reported for each publication time interval. For each sequential subsampling iteration, whenever a collection from a new publication was drawn from the occurrence list, subsequent collections were sampled until exactly three collections from that publication had been selected (Alroy 2010a). We set a baseline quorum of 0.4 , as this has been widely used and demonstrated to be sufficient in accurately assessing changes in diversity (Alroy 2010c; Alroy 2010a; Mannion et al. 2015; Nicholson et al. 2015; Tennant et al. 2016a). Diversity estimates are not reported for any analyses in which this quorum could not be attained. This dual method of using raw and standardised data is important, as not all publications name new taxa; some add to our knowledge of existing taxa by publishing on new occurrences in different collections (or sites). Therefore, by applying a method that accounts for changes in taxonomic abundance across collections we can see how publication history influences diversity through subsampling methods. 
215 For our model-fitting protocol, we follow the procedure outlined in numerous recent analytical studies,

216 by employing simple pairwise correlation tests to the residuals of detrended time series at the stage 217 level (Benson \& Butler 2011; Butler et al. 2011; Butler et al. 2013; Mannion et al. 2015; Tennant et al. 218 2016a). Residuals for each of the two environmental extrinsic parameters were calculated using the 219 arima() function in $\mathrm{R}$, which uses maximum likelihood to fit a first-order autoregressive model to each 220 time series (Gardner et al. 1980). This method detects the potential influence of any long-term background trend (i.e., a directed change in the mean value of the complete time series through time) within the time series, which has the potential to artificially inflate correlation coefficients in pairwise tests (Box \& Jenkins 1976), and also accounts for any potential serial autocorrelation (i.e., the correlation of a variable with itself through successive data points). This protocol has become standard practice now for palaeontological time series analysis following its recommendation by Alroy (2000a). For sea level, we used the curve of Miller et al. (2005), which has been widely applied in recent analyses of tetrapod diversification (Benson et al. 2010; Butler et al. 2011; Martin et al. 2014; Mannion et al. 2015; Tennant et al. 2016a), and for palaeotemperature we used the data from Prokoph et al. (2008), available as Stage level data from Hannisdal \& Peters (2011) (SI 6).

We performed an assessment of normality for each time series prior to any correlation analyses, using the Shapiro-Wilk test (shapiro.test() function in R). From the output, if the p-values are greater than the pre-defined alpha level (traditionally, 0.05, and used here) this implies that the distribution of the data are not significantly different from a normal distribution, and therefore we can assume normality and use Pearson's test (Pearson's product moment correlation coefficient [r]). If $p>0.05$, we performed a non-parametric Spearmans rank correlation $(\rho)$. For each test, both the raw and adjusted $p$-values are reported, the latter calculated using the p.adjust() function, and using the 'BH' model (Benjamini \& Hochberg 1995). This method accounts for the false-discovery test when performing multiple hypothesis tests with the same data set, which can inflate type-1 error (i.e., in order to avoid falsely rejecting a true null hypothesis; a false positive). We avoided the more commonly used 'Bonferroni correction', due to the undesirable property it has of potentially increasing type 2 error to unacceptable levels (Nakagawa 2004). This adjustment was performed on 'families' of analyses (i.e., non-independent tests), rather than on all correlation tests together, to avoid setting the pass rate for statistical significance too low.

We performed pairwise correlations for the detrended subsampled diversity estimates at each two year iteration for each group to assess how the strength and direction of correlation changes through publication history. We do not use a maximum likelihood model fitting approach because rather than 
246 trying to distinguish between a set of candidate models, we are simply assessing how the strength of

247 correlations changes through publication history.

248 All analyses were carried out in R version 3.0.2 (R Development Core Team 2013) using the functions 249 available in the default stats package..

\section{Results}

252

253

254

255

256

257

258

259

260

261

262

263

264

265

266

267

268

269

270

271

272

273

\section{Occurrences and genera through time}

From the first dinosaur discoveries until around 1950, the number of dinosaur occurrences published steadily increased through time (Fig. 1). From the mid-to the end of $20^{\text {th }}$ century, the number of published occurrences has increased substantially. This is mostly due to the publication of theropod and ornithischian occurrences, which reached a peak around the turn of the millennium, with occurrences of all three groups remaining high but declining in rate of publication after this. A very similar pattern is observed for genera, with the publication of newly named genera increasing exponentially since around 1990, and at an equal rate for all three groups (Fig. 2). The cumulative frequency of newly named genera shows that, although the rate of growth remains approximately similar and increasing for all three groups, there are times when the relative overall number of genera between groups changes through publication history. For example, while sauropodomorphs had more named genera than theropods until around 1935, this changed at around 1960 when new theropod genera became more frequently published than sauropodomorphs. The recent rate of growth of newly named theropod genera in the last 15 years means that they are now named as frequently as newly named ornithischian genera. This recent rate of growth in the naming of new taxa is distinct from the patterns of taxonomic invalidation (e.g., through synonymy) that have occurred since 1991 (Fig. 3). While we see an increase in the number of invalidated taxa between 2000 and 2010, this is variable for each group, with theropods peaking in 2007, sauropodomorphs peaking in 2002 to 2004, and ornithischians in 2007 and 2013.

[Figure 1 - Occurrences through time]

[Figure 2-Genera through time]

[Figure 3-Invalid taxa through time]

'Global' patterns of total dinosaur diversity 
274 Apparent 'global' empirical dinosaur diversity steadily rises until the end of the Jurassic (Fig. 4A).

275 Diversity is low across the $\mathrm{J} / \mathrm{K}$ interval until the Hauterivian, before recovering in the late Early

276 Cretaceous. There is a second decline through the late Early to early Late Cretaceous interval, before

277 diversity increases to its zenith in the latest Cretaceous. This general pattern remains constant

278 throughout publication history, although diversity in the 'middle' Cretaceous and latest Cretaceous

279 intervals shows the greatest increases. Subsampled global dinosaur diversity retains this overall pattern

280 (Fig. 4B). The J/K interval decline is still visible, but the late Early Cretaceous apparent diversity increase

281 supersedes Late Jurassic levels. The early Late Cretaceous decline is also still present, but the magnitude

282 of the latest Cretaceous diversity increase is much lower than that recovered for the empirical data. The

283 reason for this distinction between subsampled and raw diversity is that SQS estimates diversity by

284 standardising coverage of the taxon-abundance distribution, and thereby reduces the impact of 285 intensely sampled time intervals such as the latest Cretaceous.

286 [Figure 4-Dinosaur global diversity]

287

Patterns of raw and subsampled diversity by group

289

290

291

292

293

294

295

296

297

298

299

300

301

302

303

\section{Ornithischians}

Raw 'global' ornithischian diversity (Fig. 5A) is constant and stable throughout publication history. The apparent magnitude of longer-term trends is obscured by the relative over-sampling of the Campanian and Maastrichtian, which are almost an order of magnitude higher than any other Jurassic or Cretaceous stage interval. Indeed, the Campanian shows no sign of slowing down in increasing diversity, and is the highest and most rapidly increasing of any time interval. In spite of this, the overall trends in raw diversity remain, with steadily increasing Middle to Late Jurassic diversity, a small earliest Cretaceous decline followed by a 'middle' Cretaceous peak in the Aptian, a shallow decline into the early Late Cretaceous, and an increase in the Campanian.

Raw diversity in Europe shows increasing diversity across the J/K transition before an earliest Cretaceous decline (Valanginian to Hauterivian), constant 'middle' Cretaceous diversity, and an increase from the Campanian to Maastrichtian (Fig. 5B). Raw African ornithischian diversity is too inconsistent to analyse any changes through geological time or publication time (Fig. 5C). Raw Asian diversity is fairly constant through the Cretaceous, until an apparent major Campanian peak and Maastrichtian decline (Fig. 5D). In North America, empirical diversity is flat and low throughout the Late Jurassic and most of the 
304 Cretaceous (Fig. 5E). There is a Campanian peak, and order of magnitude higher than any prior interval, 305 which is rapidly increasing through publication time. Diversity decreases from this into the Maastrichtian, 306 in which diversity has remained relatively stable through publication time. Sampling in South America is 307 also relatively poor, with apparent diversity remaining low and flat where a signal is obtained (Fig. 5F).

308 [Figure 5 - Ornithischians, raw]

309 Subsampled 'global' ornithischian diversity shows a distinctly different pattern from the raw curve, both 310 in terms of overall trends, and in terms of the magnitude of the effect of publication history (Fig. 6A). 311 The Jurassic is generally too poorly sampled to reveal a constant signal, but there is evidence of a decline 312 through the Jurassic/Cretaceous transition, which remains constant through publication time. This is 313 followed by a middle-Cretaceous increase, in which ornithischian diversity is at its second highest level 314 throughout their history. The magnitude of this Albian radiation has rapidly increased over publication 315 time, the result being that originally what appeared to be increasing subsampled diversity over the 316 Early/Late Cretaceous transition now shows a major decline from the Albian to Coniacian. Santonian 317 subsampled diversity remains unknown, but when we see a signal emerge in the Campanian, diversity is 318 higher than the Albian, reaching its highest level before declining by more than half into the 319 Maastrichtian. This overall structure, besides the Albian, remains consistent throughout publication time with no major perturbations to the apparent 'global' curve.

321 [Figure 6 - Ornithischians, SQS]

322 Subsampled European diversity reveals increasing diversity across the Tithonian/Berriasian transition, 323 followed by overall gradually decreasing diversity throughout the remainder of the Early Cretaceous (Fig. 324 6B). In Africa, the signal is too poor to reveal anything besides a Kimmeridgian/Tithonian subsampled 325 diversity drop (Fig. 6C), and in Asia, there is evidence of a decline in subsampled diversity across the 326 Albian/Cenomanian transition (Fig. 6D). In North America, subsampled diversity reveals a decline across 327 the Early-Late Cretaceous transition, and a major decline from the Campanian to Maastrichtian, a 328 pattern that remains stable through publication history (Fig. 6E). In South America, the subsampled 329 signal is too poor to comment on ornithischian diversity (Fig. 6F).

330 If we look at how coverage has changed through publication history (based on Good's $u$ ), we should expect that subsampled diversity patterns are reflective of this pattern. At a global level, coverage in the 332 Cretaceous is much better than the Jurassic (Fig. 7A). Much of this, however, is based on patchy regional 333 records. In Europe, we find that coverage increases across the J/K interval (Fig. 7B), and is the only place 
334 where a consistently reliable record here can be obtained. In Africa, coverage is generally poor, besides

335 in the latest Jurassic (Fig. 7C). In Asia, coverage is poor up until the late Early Cretaceous (Fig. 7D). In

336 North America, coverage is good in the latest Jurassic and 'middle' to Late Cretaceous, but non-existent

337 in Early to Middle Jurassic and earliest Cretaceous (Fig. 7E). Coverage is generally poor for the entire

338 South American ornithischian record (Fig. 7F), explaining why obtaining a subsampled diversity signal

339 here is difficult.

340 [Figure 7-Ornithischia, u]

341

342

Theropods

343 The overall shape of the raw 'global' theropod diversity curve remains consistent through publication 344 history for the Jurassic (Fig. 8A), similar to ornithischians, where we see steadily increasing Middle to 345 Late Jurassic diversity. 'Middle' Cretaceous raw diversity fluctuated, followed by a major Campanian to 346 Maastrichtian rise. The lowest apparent diversity is in the Coniacian, reaching earliest Cretaceous levels.

347 Notable variations due to publication history are in the Barremian to Cenomanian, where diversity 348 increases in magnitude through time, gradually exceeding that for Late Jurassic diversity. Raw European 349 diversity is fairly constant through publication history (Fig. 8B), with a Middle Jurassic diversity peak in 350 the Bathonian, followed by a Callovian-Oxfordian trough, a second larger Kimmeridgian peak, and then 351 constant decline from the Tithonian to the Valanginian. Barremian diversity is increases through 352 publication time, and is as high as Kimmeridgian levels. Aptian and Albian diversity is relatively low 353 through publication history. Campanian and Maastrichtian diversity levels are slowly increasing through 354 publication history. As with ornithischians, African theropods are generally too poorly sampled at the 355 stage level to recognise any consistent empirical patterns (Fig. 8C). There is a Cenomanian raw diversity 356 spike, but how this compares with much of the rest of the Cretaceous is obscured by patchy sampling. In 357 Asia, raw Late Jurassic diversity is generally lower than for the Cretaceous (Fig. 8D). The Cretaceous sees 358 three peaks in apparent diversity during the Aptian, Turonian and Campanian-Maastrichtian, with the 359 latter being considerably higher than any previous one, and growing rapidly through publication history. 360 In North America, raw diversity levels are dwarfed by the intensive sampling of latest Cretaceous 361 theropods, with major gaps in the Middle to Late Jurassic and earliest Cretaceous records (Fig. 8E). 362 Campanian and Maastrichtian raw diversity is constantly increasing at a faster rate than any other time 363 interval, and consistently reveals a slight apparent diversity decline into the end-Cretaceous. Raw South 
364 American diversity estimates are changing rapidly through publication history, with almost every 365 interval in which dinosaurs are available to be sampled doubling or tripling since 1991 (Fig. 8F). Of note 366 is a recently emerging Late Jurassic theropod fossil record in South America, which at the present 367 reveals an apparent low diversity.

368 [Figure 8-Theropoda, raw]

369 When subsampling is applied, in the Late Jurassic we see a switch from steadily increasing subsampled 370 diversity to a major Oxfordian peak and subsequent decline in diversity through the $\mathrm{J} / \mathrm{K}$ transition 371 decline, a pattern that is consistently recovered through publication time (Fig. 9A). Subsampled diversity 372 is at its highest level during the Aptian than at any other stage during theropod history, and has doubled 373 in the last 20 years of publication history. Campanian and Maastrichtian diversity are as high as the 374 Cenomanian, a pattern that remains consistent through publication time. We see the 'global' J/K 375 transition decline reflected in Europe (Fig. 9B), and a strong Barremian peak, which is not captured on a 376 'global' scale. Latest Triassic subsampled diversity is higher than at any other point in the Jurassic in 377 Europe. Maastrichtian subsampled diversity remains high, reaching the same level as that for the 378 Kimmeridgian. In Africa, as with ornithischians the signal is very patchy after subsampling is applied (Fig. 379 9C), but captures an Albian-Cenomanian diversity increase, which remains constant throughout 380 publication history, and flat diversity in the latest Cretaceous. The subsampled theropod diversity signal 381 is also patchy in Asia, but does reveal a very high latest Cretaceous diversity level, which is not otherwise 382 seen throughout theropod evolutionary history (Fig. 9D). In North America, the subsampled record is as patchy as that for ornithischians, but remains stable through publication history (Fig. 9E). Here, we see slightly increasing subsampled diversity in the latest Jurassic, a large decline from the Aptian to Albian, and a major diversification from the Santonian to Campanian. In South America a subsampled diversity signal is almost entirely absent, although we do see a reduction in almost half from the Norian to Rhaetian, which remains stable through publication history (Fig. 9F).

388 [Figure 9-Theropoda, SQS]

Theropod coverage levels are quite patchy at the 'global' level, remaining constant in the Late Triassic, 390 fluctuating in the Middle Jurassic to earliest Cretaceous, but remaining fairly stable in the 'middle' and latest Cretaceous through publication history (Fig. 10A). On a regional level, this apparent 'global' signal across the Jurassic/Cretaceous transition is again emphasised in Europe, but in the Valanginian and 393 Albian, coverage is getting notably worse through publication history (Fig. 10B). Coverage in Africa (Fig. 
394 10C) and Asia (Fig. 10D) is very patchy, and does not appear to have changed in the last 20 years overall,

395 besides the origin of moderate coverage levels in the Oxfordian and Aptian of Asia. In North America, 396 coverage levels are moderately high in the latest Jurassic, Aptian and Albian, and latest Cretaceous, only 397 improving in the latest Jurassic through publication history (Fig. 10E). In South America, coverage is 398 generally poor throughout the Jurassic and Cretaceous, but appears to be declining in the Norian and 399 Rhaetian theropod records (Fig. 10F).

400 [Figure $10-$ Theropoda, u]

\section{Sauropodomorphs}

402 Sauropodomorph empirical diversity emphasises some more changes in raw patterns through 403 publication time, particularly in the 'middle' and Late Cretaceous (Fig. 11A). Late Jurassic patterns are 404 fairly consistent, with a rising Kimmeridgian and Tithonian raw diversity emphasising an apparent major 405 decline across the $\mathrm{J} / \mathrm{K}$ interval. In Europe, sauropods show a consistent and major decline in raw diversity from the Kimmeridgian to the Berriasian (Fig. 11B). Much of the rest of the Cretaceous is too poorly sampled, but raw sauropod diversity never attains Kimmeridgian levels in Europe for the rest of their evolutionary history. Sauropodomorph dinosaurs are generally better sampled than theropods and ornithischians in Africa, showing an apparent decline through the Triassic/Jurassic transition, a latest Jurassic raw diversity peak, and low levels through the 'middle' to Late Cretaceous transition (Fig. 11C). In Asia, raw taxonomic diversity is generally low compared to the Maastrichtian, in which diversity is relatively high and still rapidly increasing through publication history (Fig. 11D). The North American sauropod record is very patchy, with the latest Jurassic showing a shift from rapidly increasing raw diversity from the Oxfordian to a slight drop from the Kimmeridgian to Tithonian (Fig. 11E). The South American Jurassic sauropod record is patchy, but raw diversity is increasing throughout the 'middle' to Late Cretaceous through publication history (Fig. 11F).

417 [Figure 11 - Sauropodomorpha, raw]

At a 'global' level, Jurassic sauropodomorph subsampled diversity remains consistent through publication history (Fig. 12A). Here, we see steadily increasing diversity levels through the Middle and

420 Late Jurassic, before a decline through the Jurassic/Cretaceous transition, which might have been 421 initiated before the $\mathrm{J} / \mathrm{K}$ boundary itself. The greatest change in subsampled diversity is in the Albian, 422 which has almost doubled in the last 20 years, with implication for the 'mid-Cretaceous sauropod hiatus' 423 (Mannion \& Upchurch 2011). Subsampling reduces the European diversity signal due to poor sampling 
424 of sauropods, although there is evidence for the sauropod decline beginning prior to the $\mathrm{J} / \mathrm{K}$ transition 425 (Fig. 12B). In Africa, when subsampling is applied, the few intervals in which a signal emerges reveal a 426 fairly constant level of diversity through the Jurassic and Cretaceous, and through publication time, with 427 the notable exception being an increase in subsampled diversity in the latest Jurassic (Fig. 12C). In Asia, 428 the signal is also fairly poor after subsampling is applied (Fig. 12D). Here, we see an increase in 429 subsampled diversity across the Triassic/Jurassic transition, and the highest diversity level is in the 430 Maastrichtian, where subsampled estimates have increased by more than double in the last 20 years. In 431 North America, the subsampled signal is highly degraded, although of note is a near doubling of Albian 432 diversity levels in the last 20 years (Fig. 12E). In South America, the signal is very inconsistent, but 433 improving through publication history, with a patchy Late Cretaceous signal beginning to emerge (Fig. 434 12F). Full subsampling results are provided in Supplementary Information 7 and 8.

435 [Fig. 12 - Sauropodomorph, SQS]

436 Sauropodomorph coverage varies greatly at the 'global' level, with high levels in the Triassic-Jurassic 437 transition, the Middle and Late Jurassic (with the exception of the Callovian), and the Maastrichtian (Fig. 438 13A). As with theropods and ornithischians, however, this is a composite of a very patchy regional 439 record. In Europe, coverage is high during the latest Triassic, Middle Jurassic, and Late Cretaceous, and 440 this does not seem to have varied with publication time (Fig. 13B). In Africa, moderate levels of coverage 441 also have not changed substantially since 1991 (Fig. 13C). In Asia, coverage is generally high in the Late 442 Jurassic, but the Cretaceous record is incredibly poor with just two data points (Aptian and 443 Maastrichtian; Fig. 13D). In North America, the latest Jurassic has high coverage levels, which are 444 increasing through publication history in the Kimmeridgian, and moderately high coverage in the Aptian 445 and latest Cretaceous (Fig. 13E). In South America, coverage is very patchy and inconsistent, with the 446 only noteworthy change through publication history being an increase for the Rhaetian interval (Fig. 447 13F).

448 [Fig. 13 - Sauropodomorph, u]

\section{Correlation results}

451 Our results find varying strength of correlation between subsampled 'global' dinosaur diversity for each 452 clade and both palaeotemperature and sea level, although the correlations are consistently weak (SI 9). 453 This lack of statistical strength occurs for subsampled diversity estimates at the two year intervals for 
454 each of ornithischians (Table 1), sauropodomorphs (Table 2), theropods (Table 3 ), and dinosaurs overall 455 (Table 4), meaning that we cannot confidently interpret anything here. The only time the results come 456 close to alpha (0.05) is for the correlation between Ornithischia and sea level during 2007-2013 $(p=$ $4570.062-0.084, \rho=0.481-0.516)$, but our correction methods reduce the strength of all our statistical 458 results.

459 [Tables 1- 4]

460

461

\section{Discussion}

The influence of sampling and publication history on dinosaur diversity estimates

463

464

465

466

467

468

469

470

471

472

473

474

475

476

477

478

479

480

481

482

483

The impact of publication history on estimates of both raw and subsampled dinosaur diversity has direct consequences for our interpretation of their evolutionary history and diversification (Benton 2008a; Tarver et al. 2011). Using a small window of historical discovery, we show that dinosaur diversity remains highly volatile in specific geographical regions and geological time, typically where sampling levels remain very uneven or the overall sampling pool is very small (Sepkoski 1993; Alroy 2000c). In poorly sampled areas, it is clear that even small changes to the data can yield substantial changes, as we are often dealing with very small total sample sizes. This is reflected much less on an apparent 'global' scale, and much more so when we look at regional signals after subsampling is applied. As the rate of dinosaur discovery is increasing (both taxonomically and for occurrences) (Figs. 1, 2), we expect this volatility to be present in the future.

As research on dinosaurs continues and new taxa are described and published from existing fossiliferous formations, raw diversity is expected to become more correlated with rock availability as result of increasing sampling effort (Raup 1977; Wang \& Dodson 2006; Benton 2015), and represents a form of publication bias (Sepkoski 1993; Alroy 2000c; Jouve et al. 2017). Research has shown that new dinosaur discoveries, and changes in their taxonomy and phylogenetic relationships, can strongly influence our understanding and interpretation of their fossil record and diversification patterns (Weishampel 1996; Tarver et al. 2011). In this study, we examined the historical trajectory of different dinosaur diversity estimates to observe whether sampling curves are beginning to stabilise or not. For raw diversity estimates, we find evidence for relatively stable patterns in spite of any 'bonanza effect' (i.e., fossil discoveries driving formation counts, especially prevalent in Lagerstätten) (Raup 1977; Benton 2015). The fact that the curves remain relatively consistent, despite the variable addition of new taxa, suggests 
484 we are seeing some form of the 'redundancy' hypothesis at play, in that fossils and sampling are non485 independent from each other, when only raw data are considered (Benton et al. 2011; Benton et al. 486 2013a; Dunhill et al. 2014; Benton 2015). Conversely, a more appropriate interpretation might be that 487 we are generally sampling fairly, or consistently, from an underlying occurrence pool through historical 488 time, or that our application of subsampling based on a standardised estimate of coverage is sufficient 489 to eliminate any such sampling biases.

490 However, what is the explanation for the diversity patterns we obtained so far, and what does the 491 variation in these patterns tell us? Generally, a dinosaur bearing formation availability effect makes the 492 Kimmeridgian, Barremian, Albian, Aptian, Campanian, and Maastrichtian the most productive stages 493 (Barrett et al. 2009; Butler et al. 2011; Upchurch et al. 2011; Tennant et al. 2016b). By counting genus 494 density (number of genera per million year), three stages from these stand out: Kimmeridgian, 495 Campanian and Maastrichtian (Taylor 2006), with Asia being the most productive continent followed 496 closely by North America, then Europe, South America, Africa, Australasia and finally Antarctica. 497 However, what is clear from our analyses is that this is not historically consistent, and prone to change 498 as new regions are opened up for exploration and discovery.

499

500

501

502

503

504

505

506

507

508

509

510

511

512

513

514

There is a well-recognised relationship between the amount of rock available for palaeontologists to search for dinosaur fossils, and how this influences our interpretations of their diversity patterns (Barrett et al. 2009; Butler et al. 2011; Mannion et al. 2011; Upchurch et al. 2011). This raises questions about the extent to which many aspects of diversity curves could be artefacts caused by changes in global sea levels, tectonics, and other geological processes related to preservational or geological megabiases (Peters \& Foote 2001; Smith et al. 2001; Smith \& McGowan 2007; Peters \& Heim 2010; Heim \& Peters 2011; Peters \& Heim 2011a; Smith et al. 2012; Smith \& Benson 2013). As a way of exploring this, Barrett et al. (2009) applied the "residuals" method (formerly designed by Smith \& McGowan (2007) for marine fossil taxa) to account for these sorts of geological biases, and demonstrated that many features of dinosaur diversity curves are sampling artefacts that reflect changes in the amount of fossiliferous rocks and thus reflect geological rather than biological signals. However, this method has received substantial criticism since, and might not be appropriate for studies of paleodiversity (Brocklehurst 2015; Sakamoto et al. 2017). However, the influence of these geological biases appears to have been largely mitigated in recent studies by considering a historically accurate account of sampling and modelling variation through time (Alroy 2010c; Alroy 2010a; Alroy 2010b; Newham et al. 2014; Mannion et al. 2015; Nicholson et al. 2015; Grossnickle \& Newham 2016; Tennant 
515 et al. 2016b). Here, sampling heterogeneity in terms of both collection effort and rock availability can be

516 accounted for through subsampling methods, which appear to capture and alleviate at least part of the 517 geological signal. These relative changes in the amount of rock available for sampling, the number and 518 abundance of different taxa, and the historical sampling intensity of different rock formations have 519 implications for the patterns of palaeobiological change that we infer from them. An interesting 520 extension of the present study, which explores historical publication bias, would be to test how the 521 historical context of sampling (e.g., outcrop area variation or availability through time, sampling 522 intensity through time) corresponds to our historical estimates of diversity.

523 We find that there are four main time periods when great caution should be applied to interpreting processes or patterns based on dinosaur diversity, based on volatility in subsampled diversity estimates and coverage levels. These are: (1) the Late Jurassic interval for theropods in Europe, North America, and Asia (Figs. 9, 10); (2) the Middle-Late Cretaceous interval for theropods in South America and Asia

527 (Figs. 9, 10); and (3) the mid-Late Cretaceous interval for ornithischians in North and South America and Asia (Figs. 6, 7); (4) the mid-Late Cretaceous for sauropodomorphs in Africa, Asia, and South America 529 (i.e., Gondwana) (Figs. 12, 13). As well as this, the Late Triassic dinosaurian record is in a state of flux at 530 the present (Baron et al. 2017), and should be interpreted carefully (Figs. 6, 9, 12). These represent the 531 times when diversity estimates are changing most rapidly due to a combination of taxonomic revision 532 and discovery-driven publication. While we cannot predict the future of dinosaur discovery, or the 533 selective nature of publication, it seems prudent to suggest that we are cautious in our interpretation of 534 events in dinosaur macroevolution in these intervals, similar to the conclusions reached by Tarver et al. 535 (2011).

Discovery influences regional patterns of dinosaur diversity through time

\section{Ornithischians}

539 The Jurassic/Cretaceous $(\mathrm{J} / \mathrm{K})$ interval decline in subsampled diversity remains constant and recognisable 540 throughout publication history, with this stability suggesting a real biological signal and not a publication 541 artefact (Tennant et al. 2016b). However, more focussed sampling needs to occur on J/K interval 542 deposits to reveal the true global signal, as much of this pattern is based on fossils exclusively from

543 historically well-sampled European localities (Tennant et al. 2016c) (Figs. 6, 10, 12). Ornithischian 544 subsampled diversity decreases steadily through the Early Cretaceous in Europe, with a possible 
545 radiation in the Campanian to Maastrichtian, perhaps explained by an increase of recent occurrences of

546 latest Cretaceous dinosaurian findings mainly in Spain, Portugal, France and Romania (Riera et al. 2009;

547 Csiki et al. 2010). However, many of these latest Cretaceous European dinosaur faunas are not

548 particularly well-resolved stratigraphically compared to the well-studied North-American sections, which

549 makes the timing of any regional extinction here and comparison with North America and Asia difficult

550 at the present. Advanced ornithischian faunas, including ceratopsians and hadrosaurids, appear to have

551 diversified extremely rapidly in the latest Cretaceous, but this is classically explained by the

552 oversampling of North American Late Campanian localities, like Dinosaur Park Formation and its

553 approximate temporal equivalents. Although a small rise in subsampled diversity is recovered from the

554 Campanian to the Maastrichtian in Europe, this is considerably less marked than the decline in North

555 America, where subsampling reveals that ornithischian diversity was actually declining from the

556 Campanian to Maastrichtian (Brusatte et al. 2015).

557 Ornithischian subsampled diversity in Asia has been increasing steadily through publication time in the

558 'middle' Cretaceous, filling in the gap from equivalent latitude European deposits at this time. This is 559 plausibly due to the radiation of Parksosauridae and Ankylopollexia clades, two of the most dominant 560 Late Cretaceous dinosaurian taxa around this time. Together with the North American record, this 561 manifests as a great global decline across the Early-Late Cretaceous interval, a pattern that was not 562 recognised until more recent years due to the discovery of more Konzentrat-Lagerstätten in Mongolia 563 and China around this time, such as the Jehol Biota (Lambert et al. 2001; Godefroit et al. 2008; Upchurch 564 et al. 2011). A perceived Late Cretaceous subsampled diversity increase for Asian taxa, particularly 565 hadrosauroids, could be due to a renaissance in the discovery of Cretaceous Asian dinosaurs over the 566 past two decades (Lloyd et al. 2008; Barrett et al. 2009; Zhou \& Wang 2010; Upchurch et al. 2011; Mo et 567 al. 2016). Despite the increasing availability of Early Cretaceous dinosaur-bearing formations (DBFs) in 568 Africa in the last 20 years (e.g., Tunisia, Niger; (Taquet \& Russell 1999; Anderson et al. 2007)), sampling 569 here is still too limited to reveal any consistent patterns in ornithischian subsampled diversity (Mannion 570 et al. 2011; Upchurch et al. 2011; Tennant et al. 2016b) (Figs. 6, 7).

571 This regional distinction could be due to the tie between ecomorphologlogical function and biological 572 diversity, as Asian hadrosauroids increased in morphological disparity during the latest Cretaceous, 573 whereas in North America large-bodied bulk-feeding ornithischians decreased in their disparity (Vavrek 574 \& Larsson 2010; Campione \& Evans 2011; Brusatte et al. 2012; Mitchell et al. 2012). In North America, 575 several abiotic factors, including extreme fluctuations of the Western Interior Sea, and the Laramide 
576 orogeny and proposed biogeographic provincialism, may have affected the evolution of North America 577 dinosaurs in distinct ways from species on other continents (Gates et al. 2012; Arbour et al. 2016), 578 meaning that the North American record is unlikely to be representative of global diversity pattern 579 (Sampson et al. 2010; Brusatte et al. 2012).

580 Theropods

581 As already shown elsewhere (Barrett et al., 2009, Brusatte et al., 2012), 'global' theropod diversity 582 trends are overall very similar to that of Ornithischia, with subsampled diversity increases during the 583 Late Jurassic (Oxfordian and Tithonian peaks punctuated by a Kimmeridgian decline), late Early 584 Cretaceous (Aptian), early Late Cretaceous (Cenomanian) and latest Cretaceous. Moderately high 585 Middle and Late Jurassic diversity subsampled levels represent the radiation of major avetheropodan 586 clades, and a wealth of new discoveries in recent years, particularly from Asia (Upchurch et al. 2011; Xu 587 et al. 2011; Carrano et al. 2012; Benson et al. 2014; Tennant et al. 2016b).

588 European subsampled theropod diversity is more constant than in other regions, with a Bajocian peak 589 followed by a Bathonian-Oxfordian trough, and a Kimmeridgian peak followed by a Tithonian to 590 Valanginian drop. This can, at least in part, be explained by an abundance of well-sampled Late Jurassic 591 formations from across Western Europe (Upchurch et al. 2011; Benson et al. 2013; Tennant et al. 2016c). 592 Barremian diversity is increasing rapidly through publication history, and is now as high as calculated for 593 the Kimmeridgian. As with the Late Jurassic, at least part of this signal represents the influence of a 594 Lagerstätten effect (e.g., Las Hoyas, Spain) (Buscalioni et al. 2008; Upchurch et al. 2011; Sánchez595 Hernández \& Benton 2012), highlighting that single, well-sampled formations can have a profound 596 historical effect on our understanding of regional diversity patterns, even when subsampling methods 597 are applied. The European Aptian-Albian record is increasing slower through time compared to the 598 Campanian-Maastrichtian. However, this might possibly change in the future, as the ichnological record 599 in southern Europe is quite abundant for the Aptian-Albian interval, and suggests a currently 600 unrecognised dinosaurian diversity present there (Dalla Vecchia 2002; Meyer \& Thuring 2003).

601 The North American theropod record is dwarfed by an oversampling of latest Cretaceous dinosaur602 bearing formations (e.g. Dinosaur Provincial Park, Hell Creek Formation). An increasingly even 603 representation of latitudinally diverse localities from the Cenomanian-Campanian of Utah, Colorado, 604 New Mexico and Mexico (e.g. Wahweap Formation), may increase the magnitude of the small 605 subsampled diversity drop through the Maastrichtian. Subsampling highlights a latest Jurassic peak in 
606 diversity (due to the abundance of remains from the well-sampled Morrison Formation; (Foster 2003)), 607 although Jurassic subsampled diversity never attains that of the Cretaceous highs during the Aptian and 608 Campanian. In contrast to Brusatte et al. (2015), who found no evidence for a progressive Campanian609 Maastrichtian decline in North American theropod faunas using similar SQS analyses (implemented in R; 610 see (Tennant et al. 2016a; Tennant et al. 2016b) and (Alroy 2010c; Alroy 2010a) for comparative 611 discussions), we find a very slight decline that remains constant through publication history, that likely 612 relates to our usage of a slightly different subsampling approach. Aptian subsampled diversity is 613 relatively high due to the more heavily sampled localities from Montana to Texas (Kirkland et al. 1997; 614 Cifelli et al. 1999; Kirkland \& Madsen 2007).

615 In Africa, there is a Cenomanian radiation (Fig. 9C) mainly due to the multitaxic theropod dominated 616 Kem Kem beds and other Albian-Cenomanian ("middle" Cretaceous) equivalents in Northern Africa, but 617 this signal might have been altered by time averaging effects constraining a more temporally diluted 618 diversity in a single unit (Mannion \& Barrett 2013; Evers et al. 2015; Chiarenza \& Cau 2016). Asian 619 subsampled diversity peaks in the Aptian, Campanian and Maastrichtian might be explained by a 620 Lagerstätten 'bonanza' effect, especially considering the high quality preservation deposits discovered 621 and heavily sampled in the last 20 years (e.g. Liaoning) (Lloyd et al. 2008; Zhou \& Wang 2010; Godefroit 622 et al. 2013; O'Connor \& Zhou 2015; Tennant et al. 2016c), although coverage remains only moderate 623 (around 0.5) in each of these intervals (Fig. 10). Similarly to the pattern in Africa and Asia, South 624 American theropod subsampled diversity stands out compared to other North America and Europe, 625 remaining relatively signal deficient. Despite an increasing rate of discovery of new taxa, which often 626 alter our knowledge of dinosaur phylogeny and biogeography from the 'middle' Cretaceous of Patagonia 627 and Brazil (Novas et al. 2005; Novas \& Pol 2005; Canale et al. 2009; Novas et al. 2013), coverage remains 628 poor at the stage level, emphasising the need for greater stratigraphic resolution of the theropod629 bearing formations here.

\section{Sauropodomorphs}

631 Subsampled diversity patterns of sauropodomorphs share some characteristics of those of theropods 632 and ornithischians, despite having a different fossil record due to taphonomic differences (i.e., larger, 633 more robust skeletons being preferentially preserved in different environmental settings) (Mannion \& 634 Upchurch 2010; Mannion \& Upchurch 2011; Dean et al. 2016). This is compounded by a difficulty in 635 assigning a large number of taxa to specific stage bins, which unfortunately excludes many of them from 636 our analyses (SI 1). Differences in diversity patterns between sauropodomorphs and ornithischians have 
637 classically been interpreted as being due to exclusive competition between the two main herbivorous 638 dinosaurian subtaxa (Butler et al. 2009), with an explosive radiation in ornithischians during the Early 639 Cretaceous resulting from the apparent decline in diversity of sauropodomorphs. In fact, the J/K 640 transition represents a major extinction 'event' for sauropodomorphs, reflecting the decline of non641 neosauropods, diplodocoids and basal macronarians (Mannion et al. 2013; Tennant et al. 2016b). 642 Sauropodomorph faunas have a low subsampled diversity in the earliest Cretaceous, coupled with a 643 generally poor fossil record (Mannion \& Upchurch 2010), but at a time when we otherwise see rapid 644 increases in theropod and ornithischian diversity and a prolonged phase of faunal turnover (Upchurch \& 645 Mannion 2012; Tennant et al. 2016b). Sauropodomorph subsampled diversity levels fluctuate from the 646 'middle' Cretaceous until the final latest Cretaceous radiation, with a possible small decline in the 647 Maastrichtian. This finding is somewhat contrary to that of Sakamoto et al. (2016) who found that their 648 decline was initiated in the Early Cretaceous, and that the diversification of titanosaurs was at an 649 insufficient rate to compensate for the overall loss of sauropodomorph lineages throughout the rest of 650 the Cretaceous. This discrepancy could be due to the differences in datasets used, and that several 651 recently named titanosaurs taxa have yet to be included in published phylogenies, or the distinction 652 between estimation diversity levels against diversification rates. However, we find that 653 sauropodomorphs are at their most diverse during the Albian (Fig. 12). Sauropodomorphs appear to be 654 overrepresented with respect to what we might expect for almost the entire duration of the Jurassic, 655 whereas the opposite is true for the Cretaceous (Mannion et al. 2011; Upchurch et al. 2011; Tennant et 656 al. 2016b). The general patterns of 'global' subsampled diversity shows a steady increase from Middle to 657 the end of Jurassic with a decline through J/K transition (Upchurch \& Mannion 2012; Tennant et al. 658 2016b). The relatively high Late Cretaceous subsampled diversity levels can at least be partially 659 explained by the constant discovery of new titanosaurian taxa, especially from Gondwanan continents 660 (Vieira et al. 2014; de Jesus Faria et al. 2015; Bandeira et al. 2016; Poropat et al. 2016), and only recently 661 a more appreciated diversity of diplodocoids (e.g., dicraeosaurids, rebbachisaurids) from relatively 662 poorly sampled regions such as Africa (Mannion \& Barrett 2013; Wilson \& Allain 2015; Ibrahim et al. 663 2016).

664 Large-bodied sauropodomorph diversity in the Tithonian is certainly influenced by the intense sampling 665 history of the North American Morrison Formation, where there is an unusually high diversity and 666 cranial disparity of megaherbivores within a relatively resource-poor environment (Button et al. 2014). 667 Here, high diversity remains in spite of our accounting for large collection biases associated with 668 Konzentrat-Lagerstätten (Alroy 2010c; Alroy 2010a), implying that sauropodomorphs reached their 
669 zenith in diversity during the Late Jurassic. Sauropodomorphs appear to be better sampled than 670 theropods and ornithischians in Africa (Fig. 13C), although their records remain largely too inconsistent 671 and patchy record to reveal any major patterns. Asian subsampled diversity is constantly low until the 672 Maastrichtian, where it increases moderately due to a series of recent discoveries from Pakistan and 673 China (Malkani 2010; Junchang et al. 2013). However, the Asian Cretaceous sauropodomorph record is 674 otherwise very poorly sampled, especially compared to ornithischians and theropods. This phenomenon 675 could be explained by a taphonomic size bias discriminating against the preservation of larger-bodied 676 animals in pre-Late Cretaceous Konservat-Lagerstätten, while they are more present although more rare 677 in the dense bone assemblages from the latest Cretaceous of Mongolia, China and India (Kidwell, 2001).

678 There is a notable subsampled diversity decline in European sauropodomorphs through the J/K 679 transition, as with other dinosaurian groups (Upchurch \& Mannion 2012; Tennant et al. 2016b). This is 680 distinct from results obtained with other methods (e.g., TRiPS, True Richness estimated using a Poisson 681 Sampling) which do not find any evidence for such a decline (Starrfelt \& Liow 2016). Subsampling also 682 reveals that sauropodomorph diversity in the latest Cretaceous of Europe was relatively flat. The 683 sauropodomorph record in South America is poor and mostly confined to the Late Cretaceous, with 684 diversity levels rising and resolution improving through publication time as coverage increases and as 685 new taxa get identified from emerging Patagonian and Brazilian deposits (Novas, 2007, 2009).

Here, it is worth noting the distinction between global and regional sauropodomorph records. On a global level, our results provide strong evidence for a substantial sauropod subsampled diversity decline from the Campanian to Maastrichtian. However, this decline is not represented in any of the regional sauropodomorph diversity signals. Instead, the 'global' signal in the Maastrichtian is comprised of a medley of regional records, which are only continuous with the Campanian record in Europe and North America. Therefore, the 'global extinction' of sauropods in the latest Cretaceous is actually due to regionally heterogeneous sampling signals that are summed into a misleading 'global' curve. A similar case can be made for the apparently 'global' radiation in the Albian, which is primarily a reflection of a well-sampled North American Albian sauropodomorph record (Fig. 12). Thus, when looking at diversity signals, interpretation of global patterns without considering structural changes on a regional level is not recommended. 
699 As we have shown, the interpretation of subsampled diversity estimates in dinosaurs is often highly 700 sensitive to changes in the taxon-abundance curve, and we can further distort this by relying on a 701 historically biased source of data for our analyses. Our overwhelmingly weak correlation results mean 702 that in no cases could we confidently reject any null hypotheses. As such, it is difficult to interpret how 703 the correlations have potentially changed through time. Some of the reasons for this might be that the 704 tests we used are inadequate for picking apart temporal trends over such a long time period, or a small 705 sample size, often with a lot of missing data. Alternatively, it suggests that sea level is a poor predictor of 706 dinosaur diversity at the stage level, and that dinosaur diversity and sea level are perhaps only related 707 on broader temporal scales (Haubold 1990; Butler et al. 2011; Tennant et al. 2016b). We also only 708 elected to use a single autocorrelation model, and it would be interesting in the future to explore 709 modelling a wider range of serial correlation structures on palaeontological data, and the impact this 710 might have on correlation analyses. Alternatively, our choice of using genus-level data might have been 711 influential (see Benton (2008a); Benson et al. (2016)), despite previous assertions that the species and 712 genus level diversity curves for dinosaurs are quite similar (Barrett et al. 2009). Future research could 713 investigate the influence that taxonomic resolution has on our interpretation of dinosaur evolution, as 714 well as the influence of changing taxonomic opinions through time (Fig. 3). In addition, as mentioned 715 above, it might simply be inappropriate to analyse 'global' correlations between diversity and extrinsic 716 parameters, due to the regionally heterogeneous nature of diversity data. However, what we do see is 717 that the strength of the relationship between sea level and subsampled diversity, despite being consistently weakly statistically supported, is contingent on the publication history of the group. This lends some support to the recent analysis of Jouve et al. (2017), who also found that small changes in the taxonomic composition of a dataset can lead to divergent interpretations of the environmental regulators of diversity, although this phenomenon requires further investigation.

722 The accuracy of the results from the Gondwanan continents should be treated with caution, as it is clear 723 that the fossil record is substantially patchier than the Laurasian record, reflected in the publication 724 histories of specimens from these regions. High-magnitude changes in even moderately well-sampled 725 intervals through publication history suggests we should acknowledge the limitations of any biological interpretations of the dinosaur record in Africa and South America until more reliable data are obtained

727 (Barrett et al. 2009; Mannion et al. 2011; Upchurch et al. 2011; Tennant et al. 2016b).

728 We did not test for how changes in the stratigraphy of dinosaur-bearing formations through time (e.g., 729 as chronological dates are found or refined) influences the structure of sampling pools in each time bin, 
730 a factor which is under-studied in palaeodiversity reconstructions (Gibert \& Escarguel 2017).

731 Furthermore, by explicitly excluding occurrences that did not fit within a single stage-level time bin, we 732 influence what data are not included in our analyses by rejecting specific formation pools from bins. This 733 will have a particularly stronger effect in formations that span multiple time bins, as well as in 734 formations that have less well-studied chronostratigraphy or less accurate dates. Furthermore, we used 735 stage-level bins that are inherently of uneven duration, as opposed to other commonly used methods 736 such as 2/9/10/million year approximately equal duration bins (Wang \& Dodson 2006; Barrett et al. 737 2009; Butler et al. 2011; Upchurch et al. 2011; Brusatte et al. 2012; Lloyd 2012; Mannion et al. 2012); 738 there is currently little consensus on which time binning methods are most appropriate for the fossil 739 record, although different bins can influence resulting diversity estimates (Tennant et al. 2016a).

740 The impact that all of these factors can have on diversity estimates is an ongoing discussion in research 741 about palaeodiversity, and exploring them all is beyond the scope of the present study. What is more 742 important for us in terms of study design was the focus on understanding the impact of a single factor 743 that could be compared through publication history, which is what we performed. That is not to say that 744 each of these factors do not also variably influence diversity estimates through time, and investigating 745 how these potential stratigraphic biases influences diversity estimates would be a useful future research 746 avenue.

\section{Conclusions}

749 In this study, we investigated diversity trends through time for three major clades of Dinosauria 750 (Ornithischia, Sauropodomorpha and Theropoda), by reducing a primary dataset of body fossil 751 occurrences by progressively removing publications at each 2 year intervals, up until 1991. By analysing 752 both empirical and subsampled curves, we have been able to see how publication history influences 753 different estimates of dinosaur diversity.

754 Subsampling reveals that there are major discrepancies between the 1991 and 2015 curves for 755 theropods in the Oxfordian, Aptian, and Cenomanian, for ornithischians in the late Early Cretaceous, and 756 for sauropods in the Albian and latest Cretaceous. However, almost without exception, these seemingly 757 continuous 'global' diversity patterns are the product of summing together different, and invariably 758 patchier, continental signals with vastly different trends, reflective of distinct geographic sampling 759 histories. In ornithischians, a J/K transition decline is based almost exclusively on European fossils, and a 
760

761

762

763

764

765

766

767

768

769

770

771

772

773

774

775

776

777

778

779

780

781

782

783

784

785

786

787

788

789

790

perceived global reduction in their diversity in the latest Cretaceous is the result of an overpowering North American signal. Similarly, 'global' subsampled theropod diversity is prevalently based on the European record, with Asia and North America contributing substantially more after the earliest Cretaceous hiatus. Theropod diversity in the latest Cretaceous is changing the most rapidly compared to any other time interval. In these places where see the most volatility in both subsampled diversity and coverage, we should be careful not to over-interpret patterns, especially in the context of apparent radiations and extinctions. Gondwanan dinosaurian faunas are still relatively poorly sampled despite intensive exploration in the last 20 years, and we expect the influence of discovery in Africa and South America to become more important in the future. Based on this, we urge caution in any evolutionary interpretations relying on Gondwanan dinosaur diversity until sampling improves.

However, the results of this study should be of interest to those who use occurrence-based compilations like the Paleobiology Database that rely heavily on the published literature, especially when ongoing research can potentially dramatically alter our understanding of the evolutionary history of dinosaurs (Baron et al. 2017). Both the addition of new taxa, and new occurrences of existing taxa, are clearly important in establishing stable and re-usable diversity curves for further research, and the maturity and growth of taxonomic datasets must be assessed prior to further macroevolutionary study (Tarver et al. 2011). By neglecting the publication history, and potential biases involved in this, we open ourselves up to potentially misinterpreting the patterns and processes involved in dinosaur evolution. In light of this, it is possible that many previous dinosaur diversity studies are likely now incorrect due to the large number of new discoveries being made every year (Figs. 1, 2). Furthermore, it is also likely that the analyses presented in this paper will be demonstrated to be wrong in several years' time, and it remains to be seen whether we will be ever able to faithfully reconstruct an accurate diversity curve for Dinosauria.

Future research could investigate the impact that variation in taxonomy, systematics, and validity of dinosaur taxa through publication history (Benton 2008a; Benton 2008b) (Fig. 3) has on diversity, and the influence that changes in the historical quality and stratigraphic resolution of the fossil record has on this. Furthermore, given the importance of sampling biases on our interpretations of the dinosaur fossil record (Barrett et al. 2009; Butler et al. 2011; Mannion \& Upchurch 2011; Upchurch et al. 2011; Benton 2015; Tennant et al. 2016b), research could look at how the relationships between sampling proxies and dinosaur diversity change through historical time. 
791

792

793

794

795

796

797

798

799

800

801

802

803

804

805

806

807

808

809

810

811

812

813

814

815

816

817

818

819

820

821

822

823

824

825

826

827

828

829

\section{Acknowledgements}

We are grateful for the combined efforts of all those who have collected Triassic-Cretaceous dinosaur data, and to those who have entered these data into the Paleobiology Database, especially J. Alroy, M. T. Carrano, P. D. Mannion, R. B. J. Benson, and R. J. Butler. We also thank J. Alroy for providing the Perl script used to perform SQS analyses. This is Paleobiology Database official publication number XXX. We would like to extend our thanks to David Button and the four other anonymous referees for their detailed and constructive reviews, as well as comments from Manabu Sakamoto, which greatly helped to improve this manuscript. We would all like to thank Serjoscha Evers for helping to come up with this idea during Progressive Palaeontology 2016 and during subsequent discussions.

\section{References}

Alroy J. 2000a. New methods for quantifying macroevolutionary patterns and processes. Paleobiology 26:707-733.

Alroy J. 2000b. New methods for quantifying macroevolutionary patterns and processes. Paleobiology 26:707-733.

Alroy J. 2000c. Successive approximations of diversity curves: ten more years in the library. Geology 28:1023-1026.

Alroy J. 2003. Global databases will yield reliable measures of global biodiversity. Paleobiology 29:26-29.

Alroy J. 2010a. Fair sampling of taxonomic richness and unbiased estimation of origination and extinction rates. In: J. Alroy GH, ed. Quantitative Methods in Paleobiology: The Paleontological Society, 55-80.

Alroy J. 2010b. Geographical, environmental and intrinsic biotic controls on Phanerozoic marine diversification. Palaeontology 53:1211-1235.

Alroy J. 2010c. The shifting balance of diversity among major marine animal groups. Science 329:11911194.

Anderson PE, Benton MJ, Trueman CN, Paterson BA, and Cuny G. 2007. Palaeoenvironments of vertebrates on the southern shore of Tethys: The nonmarine Early Cretaceous of Tunisia. Palaeogeography, Palaeoclimatology, Palaeoecology 243:118-131.

Arbour VM, Zanno LE, and Gates T. 2016. Ankylosaurian dinosaur palaeoenvironmental associations were influenced by extirpation, sea-level fluctuation, and geodispersal. Palaeogeography, Palaeoclimatology, Palaeoecology 449:289-299. 10.1016/j.palaeo.2016.02.033

Bandeira KL, Simbras FM, Machado EB, de Almeida Campos D, Oliveira GR, and Kellner AW. 2016. A New Giant Titanosauria (Dinosauria: Sauropoda) from the Late Cretaceous Bauru Group, Brazil. PloS one 11:e0163373.

Baron MG, Norman DB, and Barrett PM. 2017. A new hypothesis of dinosaur relationships and early dinosaur evolution. Nature 543:501-506.

Barrett PM, McGowan AJ, and Page V. 2009. Dinosaur diversity and the rock record. Proceedings of the Royal Society Series B: Biological Sciences 276:2667-2674. DOI 10.1098/rspb.2009.0352 
830

831

832

833

834

835

836

837

838

839

840

841

842

843

844

845

846

847

848

849

850

851

852

853

854

855

856

857

858

859

860

861

862

863

864

865

866

867

868

869

870

871

872

873

874

875

876

Benjamini Y, and Hochberg Y. 1995. Controlling the false discovery rate: a practical and powerful approach to multiple testing. Journal of the Royal Statistical Society Series B (Methodological) 57:289-300.

Benson RB, Campione NE, Carrano MT, Mannion PD, Sullivan C, Upchurch P, and Evans DC. 2014. Rates of dinosaur body mass evolution indicate 170 million years of sustained ecological innovation on the avian stem lineage. PLOS Biology 12:e1001853.

Benson RB, and Upchurch P. 2013. Diversity trends in the establishment of terrestrial vertebrate ecosystems: interactions between spatial and temporal sampling biases. Geology 41:43-46.

Benson RBJ, and Butler RJ. 2011. Uncovering the diversification history of marine tetrapods: ecology influences the effect of geological sampling biases. In: McGowan AJ, and Smith AB, eds. Comparing the Geological and Fossil Records: Implications for Biodiversity Studies: Geological Society of London, Special Publications, 191-208.

Benson RBJ, Butler RJ, Alroy J, Mannion PD, Carrano MT, and Lloyd GT. 2016. Near-stasis in the longterm diversification of Mesozoic tetrapods. PLOS Biology 14:e1002359.

10.1371/journal.pbio.1002359

Benson RBJ, Butler RJ, Lindgren J, and Smith AS. 2010. Mesozoic marine tetrapod diversity: mass extinctions and temporal heterogeneity in geological megabiases affecting vertebrates. Proceedings of the Royal Society Series B: Biological Sciences 277:829-834. DOI 10.1098/rspb.2009.1845

Benson RBJ, Mannion PD, Butler RJ, Upchurch P, Goswami A, and Evans SE. 2013. Cretaceous tetrapod fossil record sampling and faunal turnover: Implications for biogeography and the rise of modern clades. Palaeogeography, Palaeoclimatology, Palaeoecology 372:88-107. DOI 10.1016/j.palaeo.2012.10.028

Benton MJ. 2008a. Fossil quality and naming dinosaurs. Biology Letters 4:729-732.

Benton MJ. 2008b. How to find a dinosaur, and the role of synonymy in biodiversity studies. Paleobiology 34:516-533.

Benton MJ. 2015. Palaeodiversity and formation counts: redundancy or bias? Palaeontology 58:10031029.

Benton MJ, Dunhill AM, Lloyd GT, and Marx FG. 2011. Assessing the quality of the fossil record: insights from vertebrates. Geological Society, London, Special Publications 358:63-94.

Benton MJ, Ruta M, Dunhill AM, and Sakamoto M. 2013a. The first half of tetrapod evolution, sampling proxies, and fossil record quality. Palaeogeography Palaeoclimatology Palaeoecology 372:18-41. DOI 10.1016/j.palaeo.2012.09.005

Benton MJ, Ruta M, Dunhill AM, and Sakamoto M. 2013b. The first half of tetrapod evolution, sampling proxies, and fossil record quality. Palaeogeography, Palaeoclimatology, Palaeoecology 372:1841. DOI 10.1016/j.palaeo.2012.09.005

Box GE, and Jenkins GM. 1976. Time Series Analysis: Forecasting and Control. San Francisco: Holden-Day. Brocklehurst N. 2015. A simulation-based examination of residual diversity estimates as a method of correcting for sampling bias. Palaeontologia Electronica 18:1-15.

Brocklehurst N, Day MO, Rubidge BS, and Fröbisch J. 2017. Olson's Extinction and the latitudinal biodiversity gradient of tetrapods in the Permian. Proc R Soc B: The Royal Society. p 20170231.

Brocklehurst N, Upchurch P, Mannion PD, and O'Connor J. 2012. The completeness of the fossil record of Mesozoic birds: implications for early avian evolution. PLOS ONE 7.

Brusatte SL, Butler RJ, Barrett PM, Carrano MT, Evans DC, Lloyd GT, Mannion PD, Norell MA, Peppe DJ, and Upchurch P. 2015. The extinction of the dinosaurs. Biological Reviews 90:628-642.

Brusatte SL, Butler RJ, Prieto-Márquez A, and Norell MA. 2012. Dinosaur morphological diversity and the end-Cretaceous extinction. Nature Communications 3:804. 10.1038/ncomms1815 
877

878

879

880

881

882

883

884

885

886

887

888

889

890

891

892

893

894

895

896

897

898

899

900

901

902

903

904

905

906

907

908

909

910

911

912

913

914

915

916

917

918

919

920

921

https://www.nature.com/articles/ncomms1815\#supplementary-information

Buscalioni A, Fregenal M, Bravo A, Poyato-Ariza F, Sanchíz B, Báez A, Moo OC, Closas CM, Evans S, and Lobón JM. 2008. The vertebrate assemblage of Buenache de la Sierra (Upper Barremian of Serrania de Cuenca, Spain) with insights into its taphonomy and palaeoecology. Cretaceous Research 29:687-710.

Butler RJ, Barrett PM, Kenrick P, and Penn MG. 2009. Testing co - evolutionary hypotheses over geological timescales: interactions between Mesozoic non - avian dinosaurs and cycads. Biological Reviews 84:73-89.

Butler RJ, Benson RBJ, and Barrett PM. 2013. Pterosaur diversity: Untangling the influence of sampling biases, Lagerstatten, and genuine biodiversity signals. Palaeogeography, Palaeoclimatology, Palaeoecology 372:78-87. DOI 10.1016/j.palaeo.2012.08.012

Butler RJ, Benson RBJ, Carrano MT, Mannion PD, and Upchurch P. 2011. Sea level, dinosaur diversity and sampling biases: investigating the 'common cause' hypothesis in the terrestrial realm. Proceedings of the Royal Society of London Series B: Biological Sciences 278:1165-1170. DOI 10.1098/rspb.2010.1754

Button DJ, Rayfield EJ, and Barrett PM. 2014. Cranial biomechanics underpins high sauropod diversity in resource-poor environments. Proc R Soc B: The Royal Society. p 20142114.

Campione NE, and Evans DC. 2011. Cranial growth and variation in edmontosaurs (Dinosauria: Hadrosauridae): implications for latest Cretaceous megaherbivore diversity in North America. PLoS One 6:e25186.

Canale JI, Scanferla CA, Agnolin FL, and Novas FE. 2009. New carnivorous dinosaur from the Late Cretaceous of NW Patagonia and the evolution of abelisaurid theropods. Naturwissenschaften 96:409-414.

Carrano MT, Benson RB, and Sampson SD. 2012. The phylogeny of Tetanurae (Dinosauria: Theropoda). Journal of Systematic Palaeontology 10:211-300.

Chao A, and Jost L. 2012. Coverage-based rarefaction and extrapolation: standardizing samples by completeness rather than size. Ecology 93:2533-2547.

Chiarenza AA, and Cau A. 2016. A large abelisaurid (Dinosauria, Theropoda) from Morocco and comments on the Cenomanian theropods from North Africa. PeerJ 4:e1754.

Cifelli RL, Nydam RL, Gardner JD, Weil A, Eaton JG, Kirkland JI, and Madsen SK. 1999. Medial Cretaceous vertebrates from the Cedar Mountain Formation, Emery County, Utah: the Mussentuchit local fauna. Vertebrate paleontology in Utah 99:219-242.

Csiki Z, Grigorescu D, Codrea V, and Therrien F. 2010. Taphonomic modes in the Maastrichtian continental deposits of the Haţeg Basin, Romania-Palaeoecological and palaeobiological inferences. Palaeogeography, Palaeoclimatology, Palaeoecology 293:375-390.

Dalla Vecchia F. 2002. Cretaceous dinosaurs in the Adriatic-Dinaric carbonate platform (Italy and Croatia): paleoenvironmental implications and paleogeographical hypotheses. Memorie della Società Geologica Italiana 57:89-100.

de Jesus Faria CC, Riga BG, dos Anjos Candeiro CR, da Silva Marinho T, David LO, Simbras FM, Castanho RB, Muniz FP, and da Costa PVLG. 2015. Cretaceous sauropod diversity and taxonomic succession in South America. Journal of South American Earth Sciences 61:154-163.

Dean CD, Mannion PD, and Butler RJ. 2016. Preservational bias controls the fossil record of pterosaurs. Palaeontology 59:225-247. 10.1111/pala.12225

Dunhill AM, Hannisdal B, and Benton MJ. 2014. Disentangling rock record bias and common-cause from redundancy in the British fossil record. Nature Communications 5:4818. 
922

923

924

925

926

927

928

929

930

931

932

933

934

935

936

937

938

939

940

941

942

943

944

945

946

947

948

949

950

951

952

953

954

955

956

957

958

959

960

961

962

963

964

965

966

967

Evers SW, Rauhut OW, Milner AC, McFeeters B, and Allain R. 2015. A reappraisal of the morphology and systematic position of the theropod dinosaur Sigilmassasaurus from the "middle" Cretaceous of Morocco. PeerJ 3:e1323.

Foster JR. 2003. Paleoecological Analysis of the Vertebrate Fauna of the Morrison Formation (Upper Jurassic), Rocky Mountain Region, USA: Bulletin 23: New Mexico Museum of Natural History and Science.

Gardner G, Harvey A, and Phillips G. 1980. Algorithm AS 154: An algorithm for exact maximum likelihood estimation of autoregressive-moving average models by means of Kalman filtering. Journal of the Royal Statistical Society Series C (Applied Statistics) 29:311-322.

Gates TA, Prieto-Márquez A, and Zanno LE. 2012. Mountain building triggered Late Cretaceous North American megaherbivore dinosaur radiation. PLoS One 7:e42135.

Gibert C, and Escarguel G. 2017. Evaluating the accuracy of biodiversity changes through geologic times: from simulation to solution. Paleobiology 43:667-692.

Godefroit P, Demuynck H, Dyke G, Hu D, Escuillié F, and Claeys P. 2013. Reduced plumage and flight ability of a new Jurassic paravian theropod from China. Nature Communications 4:1394.

Godefroit P, Shulin H, Tingxiang Y, and Lauters P. 2008. New hadrosaurid dinosaurs from the uppermost Cretaceous of northeastern China. Acta Palaeontologica Polonica 53:47-74.

Good IJ. 1953. The population frequencies of species and the estimation of population parameters. Biometrika 403:237-264.

Gould SJ, and Eldredge N. 1977. Punctuated equilibria: the tempo and mode of evolution reconsidered. Paleobiology 3:115-151.

Gradstein FM, Ogg JG, Schmitz M, and Ogg G. 2012. The Geologic Time Scale 2012: Elsevier.

Grossnickle DM, and Newham E. 2016. Therian mammals experience an ecomorphological radiation during the Late Cretaceous and selective extinction at the K-Pg boundary. Proc R Soc B: The Royal Society. p 20160256.

Hannisdal B, and Peters SE. 2011. Phanerozoic Earth system evolution and marine biodiversity. Science 334:1121-1124. DOI 10.1126/science.1210695

Haubold H. 1990. Dinosaurs and fluctuating sea levels during the Mesozoic. Historical Biology 4:75-106.

Heim NA, and Peters SE. 2011. Covariation in macrostratigraphic and macroevolutionary patterns in the marine record of North America. Geological Society of America Bulletin 123:620-630.

Ibrahim N, Dal Sasso C, Maganuco S, Fabbri M, Martill DM, Gorscak E, and Lamanna M. 2016. Evidence of a derived titanosaurian (Dinosauria, Sauropoda) in the "Kem Kem beds" of Morocco, with comments on sauropod paleoecology in the Cretaceous of Africa. Cretaceous Period: Biotic Diversity and Biogeography New Mexico Museum of Natural History and Science Bulletin, 149159.

Jouve S, Mennecart B, Douteau J, and Jalil N-E. 2017. Biases in the study of relationships between biodiversity dynamics and fluctuation of environmental conditions. Palaeontologia Electronica 20:1-21.

Junchang L, Laiping Y, Hui Z, and Xuefang W. 2013. A new somphospondylan sauropod (Dinosauria, Titanosauriformes) from the Late Cretaceous of Ganzhou, Jiangxi Province of southern China. Acta Geologica Sinica (English Edition) 87:678-685.

Kirkland JI, Britt B, Burge DL, Carpenter K, Cifelli R, DeCourten F, Eaton J, Hasiotis S, and Lawton T. 1997. Lower to middle Cretaceous dinosaur faunas of the central Colorado Plateau: a key to understanding 35 million years of tectonics, sedimentology, evolution, and biogeography. Brigham Young University Geology Studies 42:69-104.

Kirkland JI, and Madsen SK. 2007. The Lower Cretaceous Cedar Mountain Formation, eastern Utah. 
968

969

970

971

972

973

974

975

976

977

978

979

980

981

982

983

984

985

986

987

988

989

990

991

992

993

994

995

996

997

998

999

1000

1001

1002

1003

1004

1005

1006

1007

1008

1009

1010

1011

1012

1013

Lambert O, Godefroit P, Li H, Shang C-Y, and Dong Z-M. 2001. A new species of Protoceratops

(Dinosauria, Neoceratopsia) from the Late Cretaceous of Inner Mongolia (PR China). Bulletin-

Institut royal des sciences naturelles de Belgique Sciences de la Terre 71:5-28.

Lloyd GT. 2012. A refined modelling approach to assess the influence of sampling on palaeobiodiversity curves: new support for declining Cretaceous dinosaur richness. Biology Letters 8:123-126. DOI 10.1098/rsbl.2011.0210

Lloyd GT, Davis KE, Pisani D, Tarver JE, Ruta M, Sakamoto M, Hone DWE, Jennings R, and Benton MJ. 2008. Dinosaurs and the Cretaceous Terrestrial Revolution. Proceedings of the Royal Society of London Series B: Biological Sciences 275:2483-2490. DOI 10.1098/rspb.2008.0715

Malkani MS. 2010. New Pakisaurus (Pakisauridae, Titanosauria, Sauropoda) remains, and Cretaceous Tertiary (KT) boundary from Pakistan. Sindh University Research Journal-SURJ (Science Series) 42.

Mannion PD, and Barrett PM. 2013. Additions to the sauropod dinosaur fauna of the Cenomanian (early Late Cretaceous) Kem Kem beds of Morocco: Palaeobiogeographical implications of the midCretaceous African sauropod fossil record. Cretaceous Research 45:49-59.

Mannion PD, Benson RB, Upchurch P, Butler RJ, Carrano MT, and Barrett PM. 2012. A temperate palaeodiversity peak in Mesozoic dinosaurs and evidence for Late Cretaceous geographical partitioning. Global Ecology and Biogeography 21:898-908.

Mannion PD, Benson RBJ, Carrano MT, Tennant JP, Judd J, and Butler RJ. 2015. Climate constrains the evolutionary history and biodiversity of crocodylians. Nature Communications 6:8438. 10.1038/ncomms9438

Mannion PD, and Upchurch P. 2010. Completeness metrics and the quality of the sauropodomorph fossil record through geological and historical time. Paleobiology 36:283-302.

Mannion PD, and Upchurch P. 2011. A re-evaluation of the 'mid-Cretaceous sauropod hiatus' and the impact of uneven sampling of the fossil record on patterns of regional dinosaur extinction. Palaeogeography, Palaeoclimatology, Palaeoecology 299:529-540.

Mannion PD, Upchurch P, Barnes RN, and Mateus O. 2013. Osteology of the Late Jurassic Portuguese sauropod dinosaur Lusotitan atalaiensis (Macronaria) and the evolutionary history of basal titanosauriforms. Zoological Journal of the Linnean Society 168:98-206.

Mannion PD, Upchurch P, Carrano MT, and Barrett PM. 2011. Testing the effect of the rock record on diversity: a multidisciplinary approach to elucidating the generic richness of sauropodomorph dinosaurs through time. Biological Reviews 86:157-181. DOI 10.1111/j.1469-185X.2010.00139.x

Martin JE, Amiot R, Lecuyer C, and Benton MJ. 2014. Sea surface temperature contributes to marine crocodylomorph evolution. Nature Communications 5:4658. 10.1038/Ncomms5658

Marx FG, and Uhen MD. 2010. Climate, critters, and cetaceans: Cenozoic drivers of the evolution of modern whales. Science 327:993-996.

Mayhew PJ, Bell MA, Benton TG, and McGowan AJ. 2012. Biodiversity tracks temperature over time. Proceedings of the National Academy of Sciences of the United States of America 109:1514115145.

Meyer C, and Thuring B. 2003. The First Iguanodontid Dinosaur Tracks from the Swiss Alps (Schrattenkalk Formation, Aptian). Ichnos 10:221-228. 10.1080/10420940390256186

Miller KG, Kominz MA, Browning JV, Wright JD, Mountain GS, Katz ME, Sugarman PJ, Cramer BS, Christie-Blick N, and Pekar SF. 2005. The Phanerozoic record of global sea-level change. Science 310:1293-1298. DOI 10.1126/science.1116412

Mitchell JS, Roopnarine PD, and Angielczyk KD. 2012. Late Cretaceous restructuring of terrestrial communities facilitated the end-Cretaceous mass extinction in North America. Proceedings of the National Academy of Sciences 109:18857-18861. 
1014

1015

1016

1017

1018

1019

1020

1021

1022

1023

1024

1025

1026

1027

1028

1029

1030

1031

1032

1033

1034

1035

1036

1037

1038

1039

1040

1041

1042

1043

1044

1045

1046

1047

1048

1049

1050

1051

1052

1053

1054

1055

1056

1057

1058

1059

1060

1061

Mo J, Buffetaut E, Tong H, Amiot R, Cavin L, Cuny G, Suteethorn V, Suteethorn S, and Jiang S. 2016. Early Cretaceous vertebrates from the Xinlong Formation of Guangxi (southern China): a review. Geological Magazine 153:143-159.

Nakagawa S. 2004. A farewell to Bonferroni: the problems of low statistical power and publication bias. Behavioral Ecology 15:1044-1045.

Newham E, Benson R, Upchurch P, and Goswami A. 2014. Mesozoic mammaliaform diversity: The effect of sampling corrections on reconstructions of evolutionary dynamics. Palaeogeography, Palaeoclimatology, Palaeoecology 412:32-44.

Nicholson DB, Holroyd PA, Benson RB, and Barrett PM. 2015. Climate-mediated diversification of turtles in the Cretaceous. Nature Communications 6:1-8. 10.1038/ncomms8848

Nicholson DB, Holroyd PA, Valdes P, and Barrett PM. 2016. Latitudinal diversity gradients in Mesozoic non-marine turtles. Royal Society Open Science 3:160581.

Novas FE, Agnolín FL, Ezcurra MD, Porfiri J, and Canale Jl. 2013. Evolution of the carnivorous dinosaurs during the Cretaceous: the evidence from Patagonia. Cretaceous Research 45:174-215.

Novas FE, de Valais S, Vickers-Rich P, and Rich T. 2005. A large Cretaceous theropod from Patagonia, Argentina, and the evolution of carcharodontosaurids. Naturwissenschaften 92:226-230.

Novas FE, and Pol D. 2005. New evidence on deinonychosaurian dinosaurs from the Late Cretaceous of Patagonia. Nature 433:858-861.

O'Connor J, and Zhou Z. 2015. Early evolution of the biological bird: perspectives from new fossil discoveries in China. Journal of Ornithology 156:333-342.

Peters SE, and Foote M. 2001. Biodiversity in the Phanerozoic: a reinterpretation. Paleobiology 27:583601.

Peters SE, and Heim NA. 2010. The geological completeness of paleontological sampling in North America. Paleobiology 36:61-79.

Peters SE, and Heim NA. 2011a. Macrostratigraphy and macroevolution in marine environments: testing the common-cause hypothesis. Geological Society, London, Special Publications 358:95-104.

Peters SE, and Heim NA. 2011b. Macrostratigraphy and macroevolution in marine environments: testing the common-cause hypothesis. In: McGowan AJ, and Smith AB, eds. Comparing the Geological and Fossil Records: Implications for Biodiversity Studies. London: Geological Society of London, 95-104.

Poropat SF, Mannion PD, Upchurch P, Hocknull SA, Kear BP, Kundrát M, Tischler TR, Sloan T, Sinapius GH, and Elliott JA. 2016. New Australian sauropods shed light on Cretaceous dinosaur palaeobiogeography. Scientific reports 6.

Prokoph A, Shields GA, and Veizer J. 2008. Compilation and time-series analysis of a marine carbonate $\delta_{18} \mathrm{O}, \delta_{13} \mathrm{C},{ }^{87} \mathrm{Sr} /{ }^{86} \mathrm{Sr}$ and $\delta^{34} \mathrm{~S}$ database through Earth history. Earth-Science Reviews 87:113-133. http://dx.doi.org/10.1016/j.earscirev.2007.12.003

R Development Core Team. 2013. R: A language and environment for statistical computing. $R$ Foundation for Statistical Computing. Vienna, Austria.

Raup DM. 1972. Taxonomic diversity during the Phanerozoic. Science 177:1065-1071.

Raup DM. 1976. Species diversity in the Phanerozoic: an interpretation. Paleobiology 2:289-297.

Raup DM. 1977. Systematists follow the fossils. Paleobiology 3:328-329.

Riera V, Oms O, Gaete R, and Galobart À. 2009. The end-Cretaceous dinosaur succession in Europe: the Tremp Basin record (Spain). Palaeogeography, Palaeoclimatology, Palaeoecology 283:160-171.

Robeck HE, Maley CC, and Donoghue MJ. 2000. Taxonomy and temporal diversity patterns. Paleobiology 26:171-187. Doi 10.1666/0094-8373(2000)026<0171:Tatdp>2.0.Co;2

Sakamoto M, Benton MJ, and Venditti C. 2016. Dinosaurs in decline tens of millions of years before their final extinction. Proceedings of the National Academy of Sciences of the United States of America 113:5036-5040. 10.1073/pnas.1521478113

PeerJ reviewing PDF | (2017:05:18196:3:0:CHECK 29 Jan 2018) 
1062

1063

1064

1065

1066

1067

1068

1069

1070

1071

1072

1073

1074

1075

1076

1077

1078

1079

1080

1081

1082

1083

1084

1085

1086

1087

1088

1089

1090

1091

1092

1093

1094

1095

1096

1097

1098

1099

1100

1101

1102

1103

1104

1105

1106

1107

1108

Sakamoto M, Venditti C, and Benton MJ. 2017. 'Residual diversity estimates' do not correct for sampling bias in palaeodiversity data. Methods in Ecology and Evolution 8:453-459. 10.1111/2041210X.12666

Sampson SD, Loewen MA, Farke AA, Roberts EM, Forster CA, Smith JA, and Titus AL. 2010. New horned dinosaurs from Utah provide evidence for intracontinental dinosaur endemism. PLoS One 5:e12292.

Sánchez-Hernández B, and Benton MJ. 2012. Filling the ceratosaur gap: A new ceratosaurian theropod from the Early Cretaceous of Spain. Acta Palaeontologica Polonica 59:581-600.

Sepkoski JJ. 1993. Ten years in the library: new data confirm paleontological patterns. Paleobiology 19:43-51.

Sepkoski JJ, Bambach RK, Raup DM, and Valentine JW. 1981. Phanerozoic marine diversity and the fossil record. Nature 293:435-437.

Sepkoski Jr JJ. 1993. Ten years in the library: new data confirm paleontological patterns. Paleobiology 19:43-51.

Sepkoski Jr JJ. 1996. Patterns of Phanerozoic extinction: a perspective from global data bases. In: Walliser OH, ed. Global Events and Event Stratigraphy in the Phanerozoic: Springer Berlin Heidelberg, 35-51.

Smith AB, and Benson RBJ. 2013. Marine diversity in the geological record and its relationship to surviving bedrock area, lithofacies diversity, and original marine shelf area. Geology 41:171-174. Doi 10.1130/G33773.1

Smith AB, Gale AS, and Monks NE. 2001. Sea-level change and rock-record bias in the Cretaceous: a problem for extinction and biodiversity studies. Paleobiology 27:241-253.

Smith AB, Lloyd GT, and McGowan AJ. 2012. Phanerozoic marine diversity: rock record modelling provides an independent test of large-scale trends. Proceedings of the Royal Society of London Series B: Biological Sciences 279:4489-4495. DOI 10.1098/rspb.2012.1793

Smith $A B$, and McGowan AJ. 2007. The shape of the Phanerozoic marine palaeodiversity curve: How much can be predicted from the sedimentary rock record of western Europe? Palaeontology 50:765-774. DOI 10.1111/j.1475-4983.2007.00693.x

Starrfelt J, and Liow LH. 2016. How many dinosaur species were there? Fossil bias and true richness estimated using a Poisson sampling model. Philosophical Transactions of the Royal Society B: Biological Sciences 371:20150219.

Taquet P, and Russell DA. 1999. A massively-constructed iguanodont from Gadoufaoua, Lower Cretaceous of Niger. Annales de Paléontologie: Elsevier. p 85-96.

Tarver J, Donoghue P, and Benton M. 2011. Is evolutionary history repeatedly rewritten in light of new fossil discoveries? Proceedings of the Royal Society of London B: Biological Sciences 278:599-604.

Taylor MP. 2006. Dinosaur diversity analysed by clade, age, place and year of description. Ninth international symposium on Mesozoic terrestrial ecosystems and biota, Manchester, UK Cambridge Publications Natural History Museum, London, UK. p 134-138.

Tennant JP, Mannion PD, and Upchurch P. 2016a. Environmental drivers of crocodyliform extinction across the Jurassic/Cretaceous transition. Proc $R$ Soc $B$ 283:20152840.

Tennant JP, Mannion PD, and Upchurch P. 2016b. Sea level regulated tetrapod diversity dynamics through the Jurassic/Cretaceous interval. Nature Communications 7.

Tennant JP, Mannion PD, Upchurch P, Sutton MD, and Price GD. 2016c. Biotic and environmental dynamics through the Late Jurassic-Early Cretaceous transition: evidence for protracted faunal and ecological turnover. Biological Reviews.

Uhen MD, and Pyenson ND. 2007. Diversity estimates, biases, and historiographic effects: resolving cetacean diversity in the Tertiary. Palaeontologia Electronica 10:1-22. 
1109

1110

1111

1112

1113

1114

1115

1116

1117

1118

1119

1120

1121

1122

1123

1124

1125

1126

1127

1128

1129

1130

1131

1132

1133

1134

1135

1136

1137

1138

1139

1140

1141

1142

1143

1144

1145

1146

1147

Upchurch P, Mannion P, Benson R, Butler R, and Carrano M. 2011. Geological and anthropogenic controls on the sampling of the terrestrial fossil record: a case study from the Dinosauria. In: McGowan AJ, and Smith AB, eds. Comparing the Geological and Fossil Records: Implications for Biodiversity Studies. London: Geological Society of London, 209-240.

Upchurch P, and Mannion PD. 2012. Dinosaur evolution and extinction across the Jurassic/Cretaceous boundary. Actas de V Jornadas Internacionales sobre Paleontología de Dinosaurios y su Entorno, Salas de los Infantes, Burgos:135-155.

Valentine J, and Moores E. 1970. Plate-tectonic regulation of faunal diversity and sea level: a model. Nature 228:657-669. 10.1038/228657a0

Van Valen LM. 1984. A resetting of Phanerozoic community evolution. Nature 307:50-52.

Vavrek MJ, and Larsson HC. 2010. Low beta diversity of Maastrichtian dinosaurs of North America. Proceedings of the National Academy of Sciences 107:8265-8268.

Vieira WLS, Vieira KS, Nobrega RP, Montenegro PFGP, Pereira Filho GA, Santana GG, Alves RRN, Almeida WO, and Vasconcellos A. 2014. Species richness and evidence of random patterns in assemblages of South American Titanosauria during the Late Cretaceous (CampanianMaastrichtian). PloS one 9:e108307.

Wang SC, and Dodson P. 2006. Estimating the diversity of dinosaurs. Proceedings of the National Academy of Sciences 103:13601-13605.

Weishampel DB. 1996. Fossils, phylogeny, and discovery: a cladistic study of the history of tree topologies and ghost lineage durations. Journal of Vertebrate Paleontology 16:191-197.

Wiese R, Renaudie J, and Lazarus DB. 2016. Testing the accuracy of genus-level data to predict species diversity in Cenozoic marine diatoms. Geology 44:1051-1054.

Wilson JA, and Allain R. 2015. Osteology of Rebbachisaurus garasbae Lavocat, 1954, a diplodocoid (Dinosauria, Sauropoda) from the early Late Cretaceous-aged Kem Kem beds of southeastern Morocco. Journal of Vertebrate Paleontology 35:e1000701.

Xu X, You H, Du K, and Han F. 2011. An Archaeopteryx-like theropod from China and the origin of Avialae. Nature 475:465-470.

Zhou Z, and Wang Y. 2010. Vertebrate diversity of the Jehol Biota as compared with other lagerstätten. Science China Earth Sciences 53:1894-1907.

\section{Figure and table captions}

Figure 1: Frequency (A) and cumulative frequency (B) of newly published dinosaur occurrences through publication time. Please note that all raw figure files (PDF) and the $\mathrm{R}$ code for generating these are available in SI 10.

Figure 2: Frequency (A) and cumulative frequency (B) of newly published dinosaur genera through publication time.

Figure 3: The number of invalidated or revised dinosaur taxa between 1991 and 2015. 
1148 Figure 4: Total dinosaur 'global' diversity patterns for a) raw and b) subsampled data. The vertical red 1149 lines represent major interval boundaries. Time stage abbreviations (in chronological order) N= Norian; $1150 \mathrm{R}=$ Rhaetian, $\mathrm{He}=$ Hettangian; $\mathrm{S}=$ Sinemurian; $\mathrm{P}=$ Pliensbachian; $\mathrm{T}=$ Toarcian; $\mathrm{A}=\mathrm{Aalenian;} \mathrm{Bj}=\mathrm{Bajocian}$; $1151 \mathrm{~B}=$ Bathonian; $\mathrm{C}=$ Callovian; $\mathrm{O}=$ Oxfordian; $\mathrm{K}=$ Kimmeridgian; $\mathrm{T} \mathrm{i}=$ Tithonian; $\mathrm{Be}=$ Berriasian; $\mathrm{V}=$ 1152 Valanginian; $\mathrm{Ha}=$ Hauterivian; $\mathrm{Ba}=$ Barremian; $\mathrm{Ap}=\mathrm{Aptian;} \mathrm{Al}=\mathrm{Albian} ; \mathrm{Ce}=$ Cenomanian; Tu= Turonian; 1153 Co= Coniacian; Sa=Santonian; Cam= Campanian; $M=$ Maastrichtian. Vertical dashed red lines indicate 1154 boundaries between different periods (Triassic/Jurassic, Jurassic/Cretaceous and Cretaceous/Paleogene).

1155 Figure 5: Raw ornithischian diversity at a) global and b-f) regional levels (Europe, Africa, Asia, North 1156 America, and South America, respectively) based on our published knowledge in 1991 and 2015. 1157 Abbreviations as Figure 4.

1158 Figure 6: Subsampled ornithischian diversity at a) global and b-f) regional levels (Europe, Africa, Asia, 1159 North America, and South America, respectively) based on our published knowledge in 1991 and 2015. 1160 Abbreviations as Figure 4.

1161 Figure 7: Good's $u$ estimates for ornithischians at A) global and B-F) regional levels (Europe, Africa, Asia, 1162 North America, and South America, respectively) based on our published knowledge in 1991 and 2015. 1163 Abbreviations as Figure 4.

1164 Figure 8: Raw theropod diversity at A) global and B-F) regional levels (Europe, Africa, Asia, North 1165 America, and South America, respectively) based on our published knowledge in 1991 and 2015. 1166 Abbreviations as Figure 4.

1167 Figure 9: Subsampled theropod diversity at A) global and B-F) regional levels (Europe, Africa, Asia, North 1168 America, and South America, respectively) based on our published knowledge in 1991 and 2015. 1169 Abbreviations as Figure 4.

1170 Figure 10: Good's $u$ estimates for theropods at A) global and B-F) regional levels (Europe, Africa, Asia, 1171 North America, and South America, respectively) based on our published knowledge in 1991 and 2015. 1172 Abbreviations as Figure 4.

1173 Figure 11: Raw sauropodomorph diversity at A) global and B-F) regional levels (Europe, Africa, Asia, 1174 North America, and South America, respectively) based on our published knowledge in 1991 and 2015. 1175 Abbreviations as Figure 4. 
1176 Figure 12: Subsampled sauropodomorph diversity at A) global and B-F) regional levels (Europe, Africa, 1177 Asia, North America, and South America, respectively) based on our published knowledge in 1991 and 1178 2015. Abbreviations as Figure 4.

1179 Figure 13: Good's $u$ estimates for sauropodomorphs at a A) global and B-F) regional levels (Europe, 1180 Africa, Asia, North America, and South America, respectively) based on our published knowledge in 1991 1181 and 2015. Abbreviations as Figure 4.

1183 Table 1. Ornithischian correlation test results.

1184 Table 2. Sauropodomorph correlation test results.

1185 Table 3. Theropod correlation tests results.

1186 Table 4. Total dinosaur correlation tests results. 
Figure 1

Frequency $(A)$ and cumulative frequency $(B)$ of newly published dinosaur occurrences through publication time.

Please note that all raw figure files (PDF) and the R code for generating these are available in SI 10.
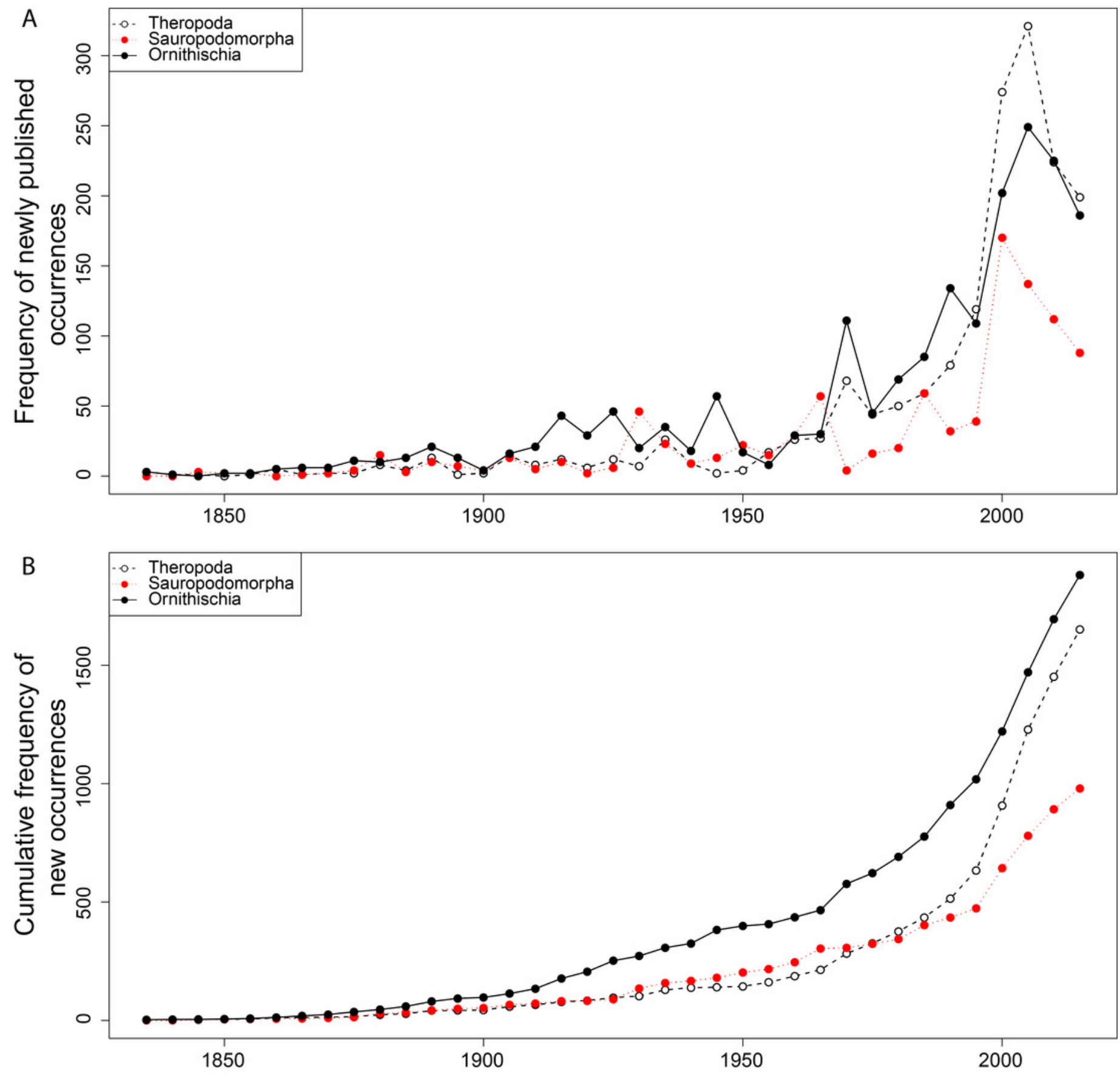
Figure 2

Frequency (A) and cumulative frequency (B) of newly published dinosaur genera through publication time.
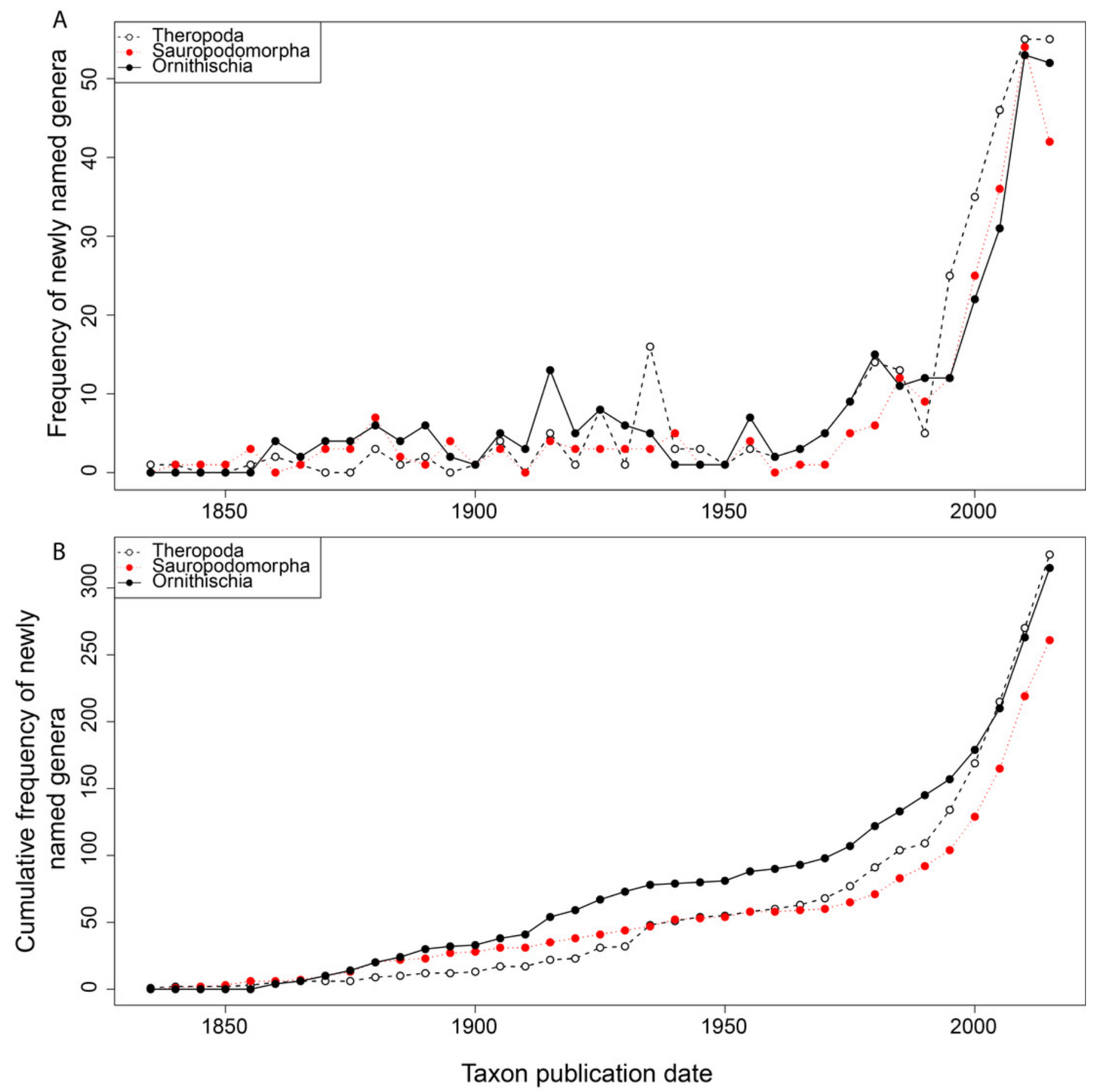
Figure 3

The number of invalidated or revised dinosaur taxa between 1991 and 2015.

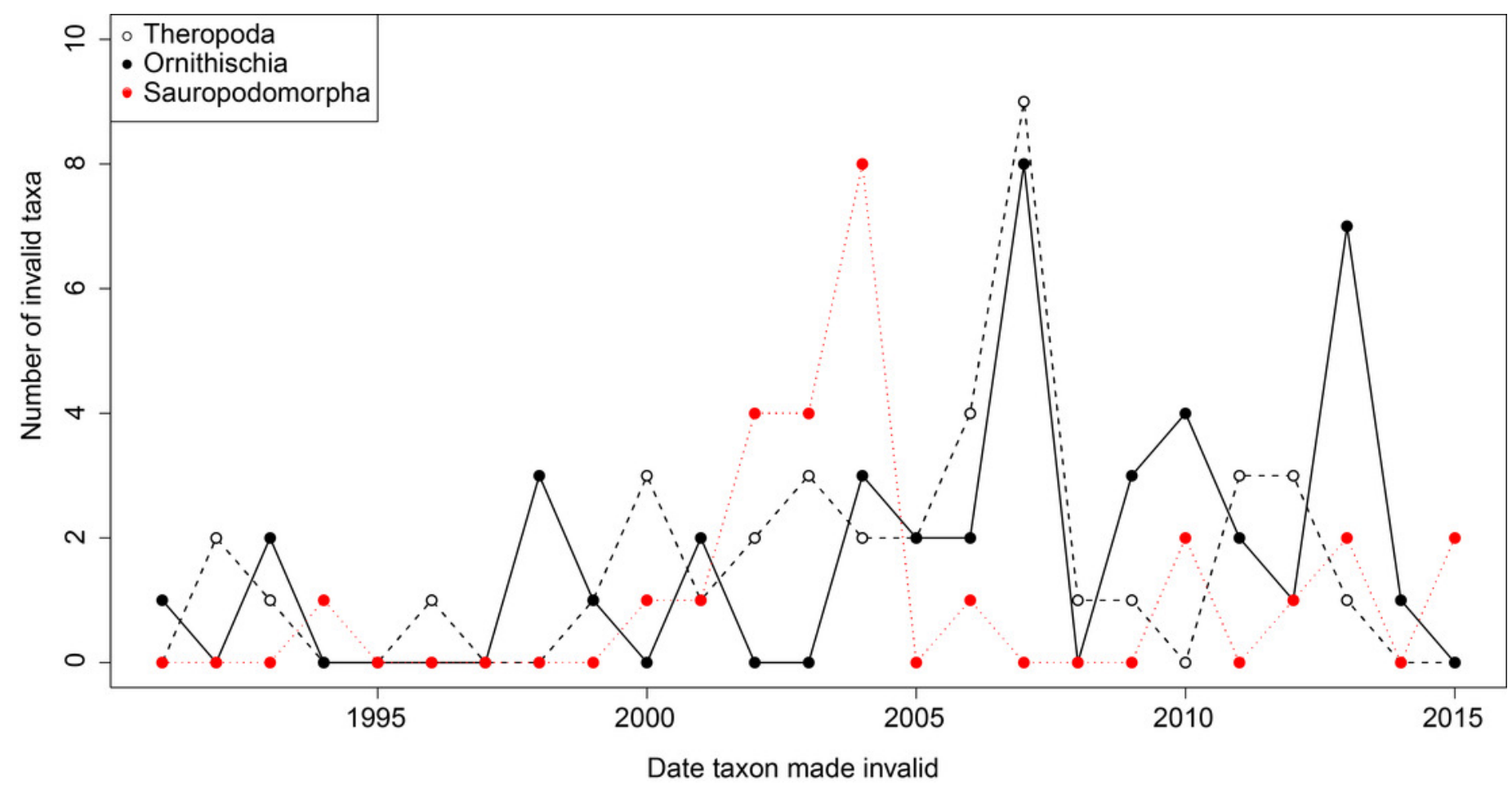




\section{Figure 4}

Total dinosaur 'global' diversity patterns for a) raw and b) subsampled data.

The vertical red lines represent major interval boundaries. Time stage abbreviations (in chronological order) $\mathrm{N}=$ Norian; $\mathrm{R}=$ Rhaetian, $\mathrm{He}=$ Hettangian; $\mathrm{S}=$ Sinemurian; $\mathrm{P}=$ Pliensbachian; $\mathrm{T}=$ Toarcian; $\mathrm{A}=$ Aalenian; $\mathrm{Bj}=$ Bajocian; $\mathrm{B}=$ Bathonian; $\mathrm{C}=$ Callovian; $\mathrm{O}=$ Oxfordian; $\mathrm{K}=$ Kimmeridgian; $\mathrm{Ti}=$ Tithonian; $\mathrm{Be}=$ Berriasian; $\mathrm{V}=$ Valanginian; $\mathrm{Ha}=$ Hauterivian; $\mathrm{Ba}=$ Barremian; $\mathrm{Ap}=\mathrm{Aptian} ; \mathrm{Al}=\mathrm{Albian} ; \mathrm{Ce}=\mathrm{Cenomanian;} \mathrm{Tu}=$ Turonian; $\mathrm{Co}=$ Coniacian; Sa= Santonian; $\mathrm{Cam}=$ Campanian; $\mathrm{M}=$ Maastrichtian. Vertical dashed red lines indicate boundaries between different periods (Triassic/Jurassic, Jurassic/Cretaceous and Cretaceous/Paleogene). 

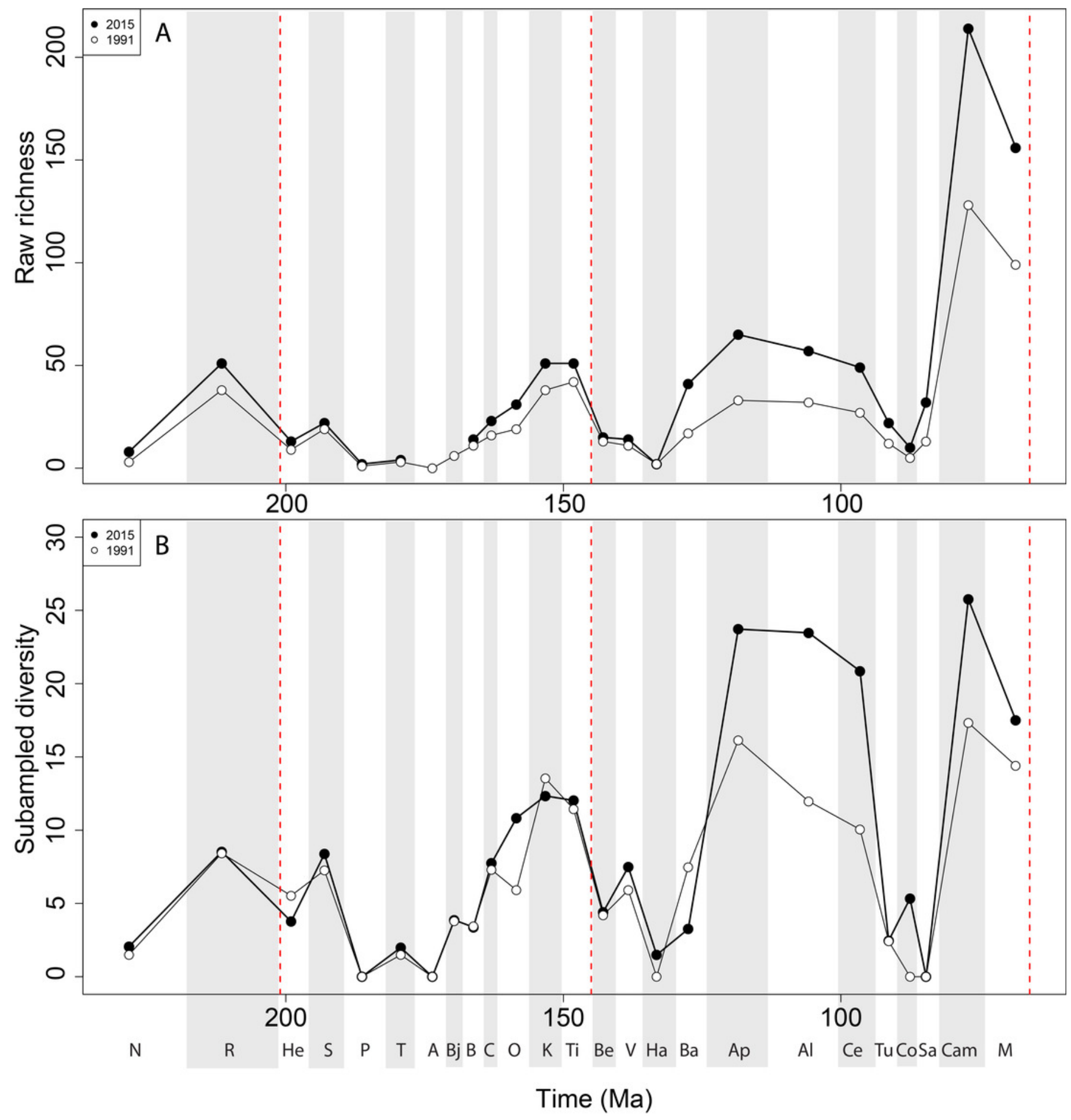
Figure 5

Raw ornithischian diversity at a) global and b-f) regional levels (Europe, Africa, Asia, North America, and South America, respectively) based on our published knowledge in 1991 and 2015.

Abbreviations as Figure 4.
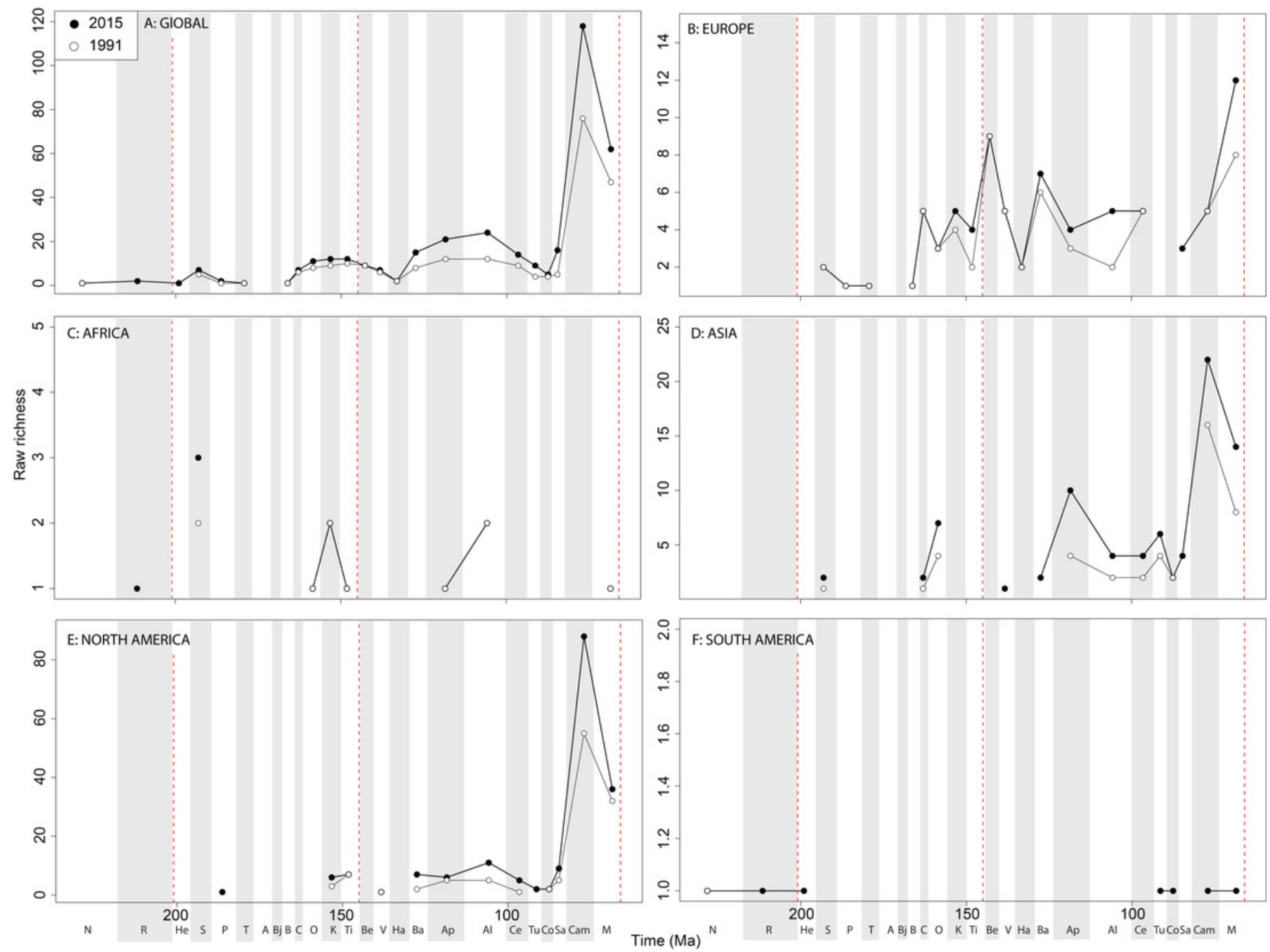
Figure 6

Subsampled ornithischian diversity at a) global and b-f) regional levels (Europe, Africa, Asia, North America, and South America, respectively) based on our published knowledge in 1991 and 2015.

Abbreviations as Figure 4.
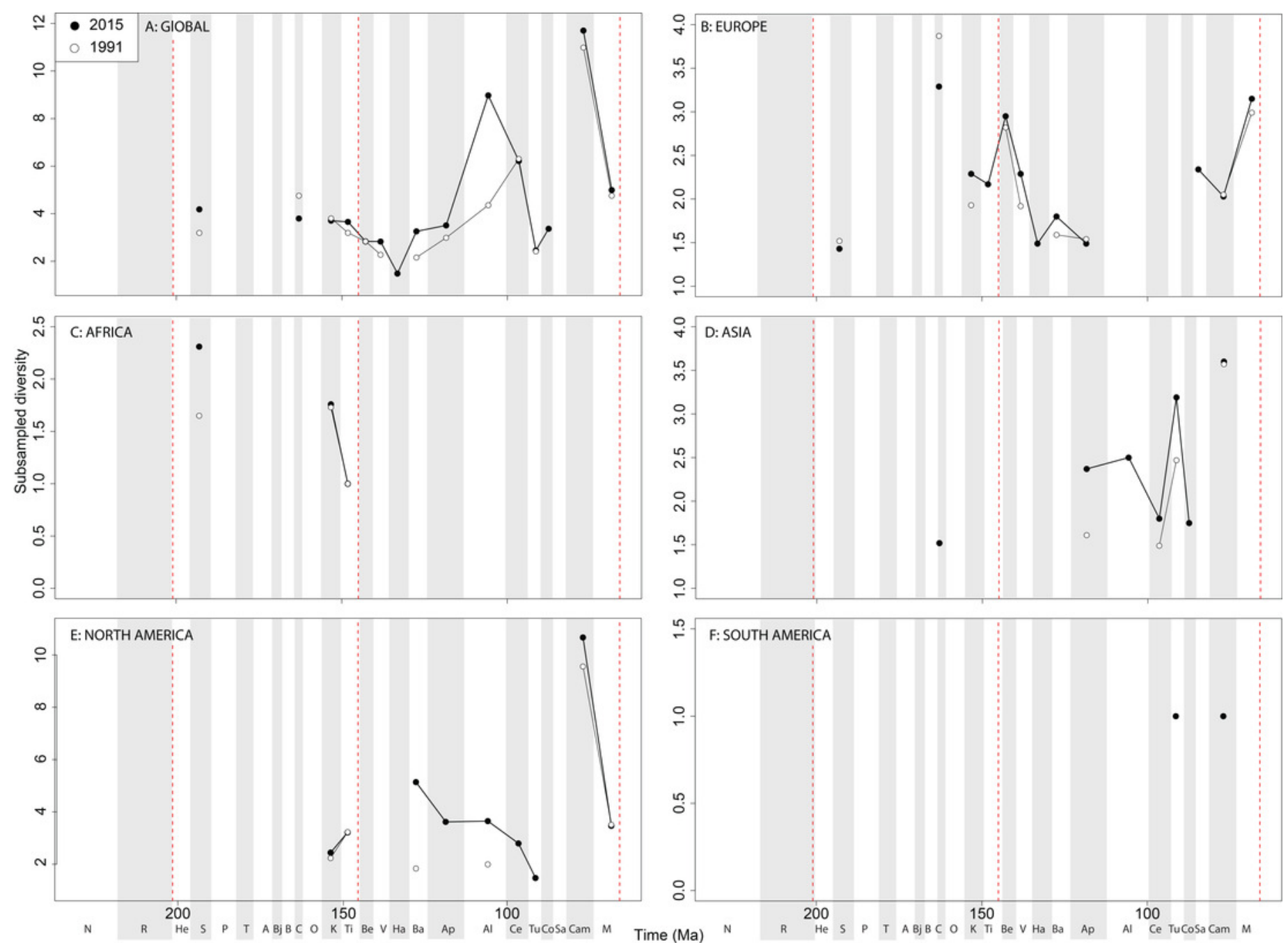
Figure 7

Good's $u$ estimates for ornithischians at A) global and B-F) regional levels (Europe, Africa, Asia, North America, and South America, respectively) based on our published knowledge in 1991 and 2015

Abbreviations as Figure 4.

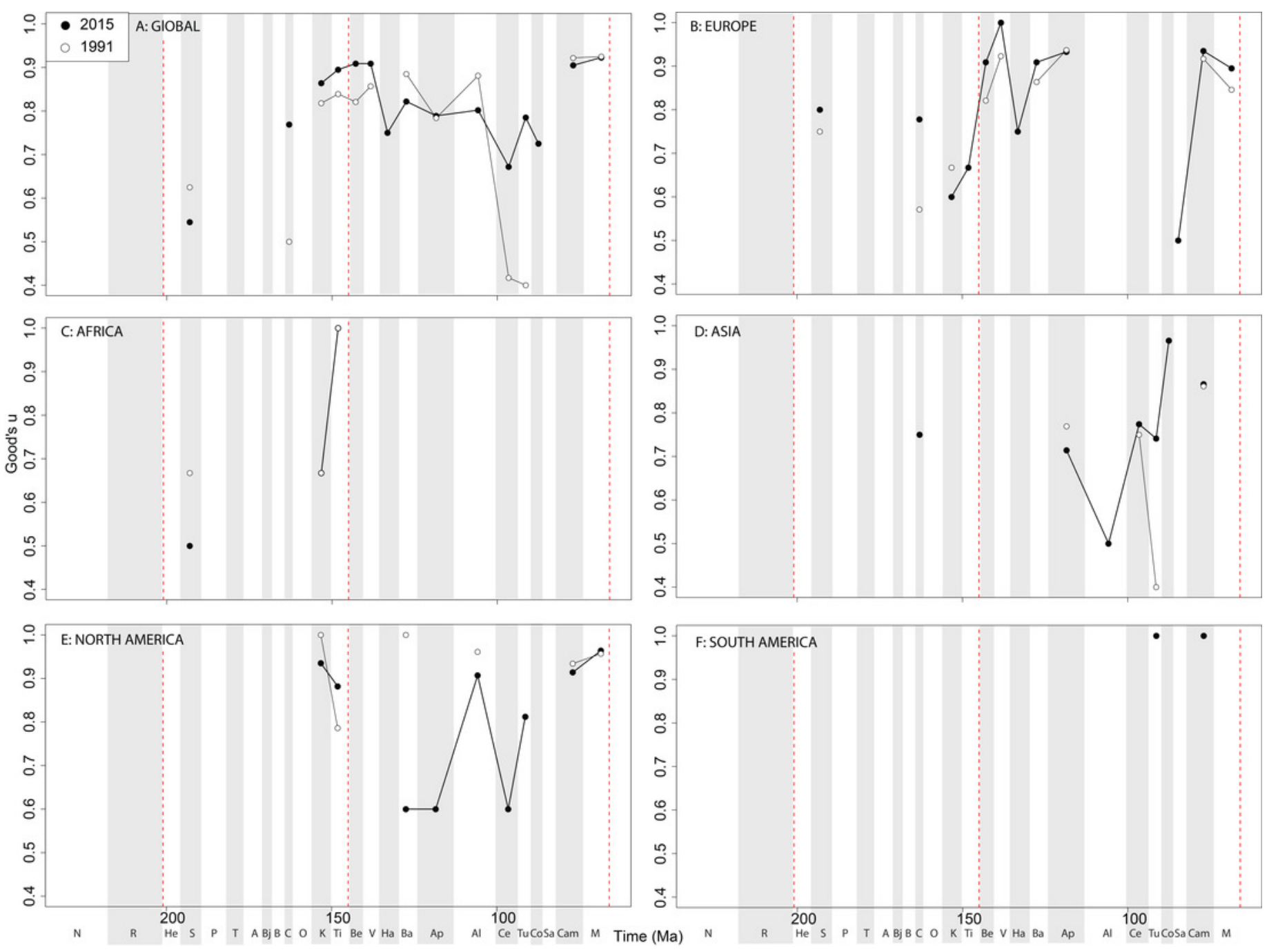


Figure 8

Raw theropod diversity at A) global and B-F) regional levels (Europe, Africa, Asia, North America, and South America, respectively) based on our published knowledge in 1991 and 2015.

Abbreviations as Figure 4.
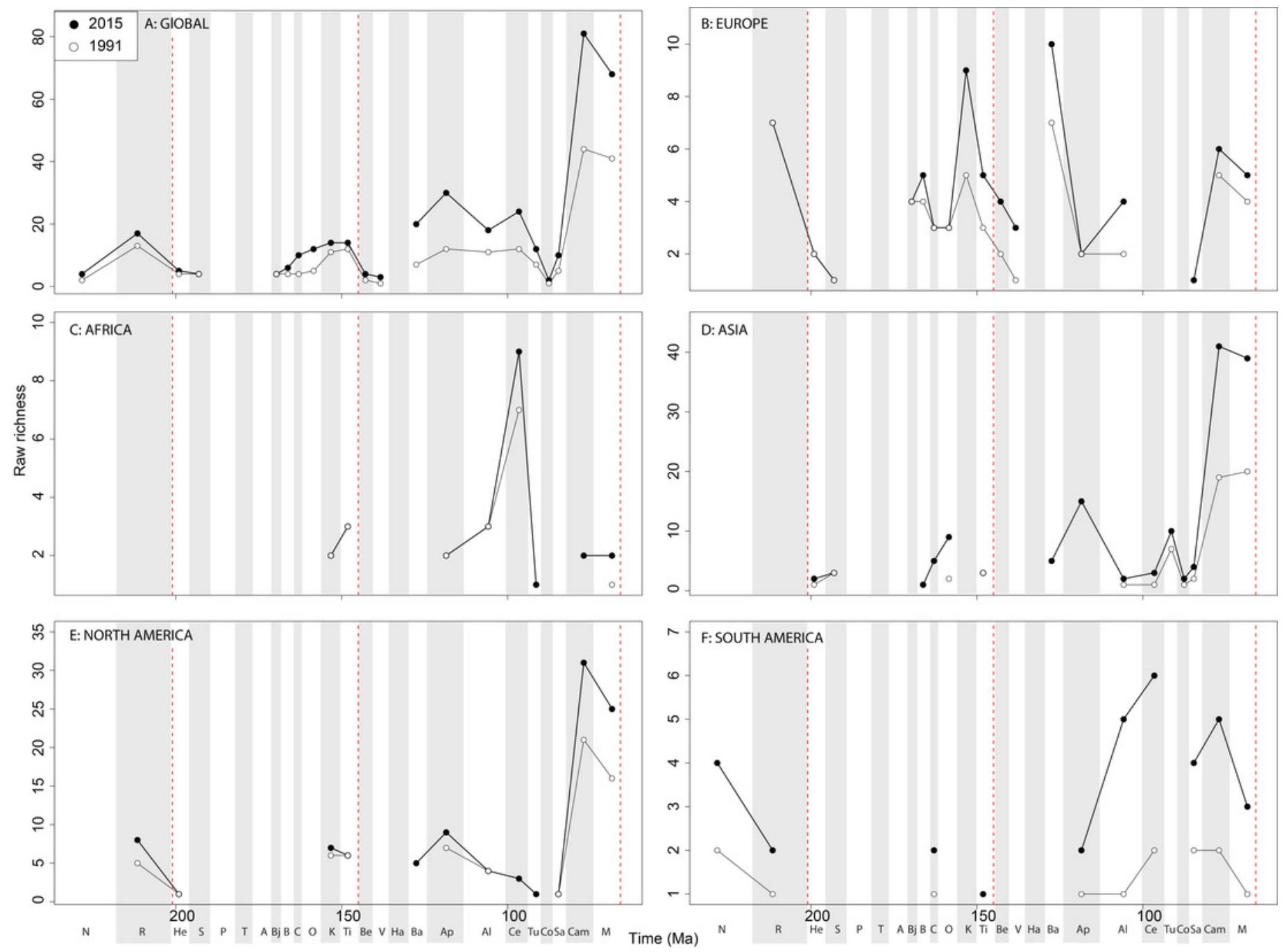
Figure 9

Subsampled theropod diversity at A) global and B-F) regional levels (Europe, Africa, Asia, North America, and South America, respectively) based on our published knowledge in 1991 and 2015

Abbreviations as Figure 4.
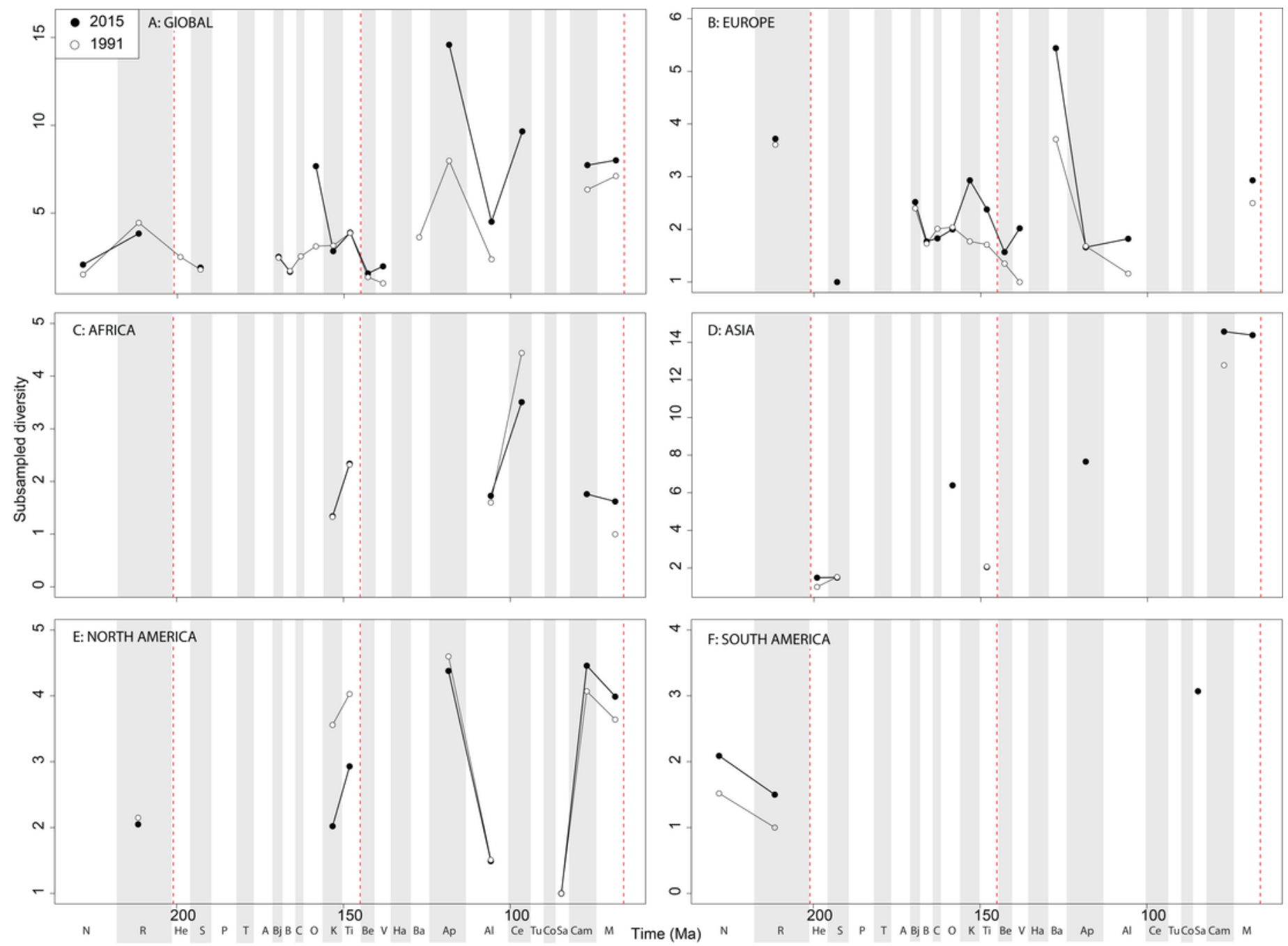
Figure 10

Good's $u$ estimates for theropods at A) global and B-F) regional levels (Europe, Africa, Asia, North America, and South America, respectively) based on our published knowledge in 1991 and 2015.

Abbreviations as Figure 4.

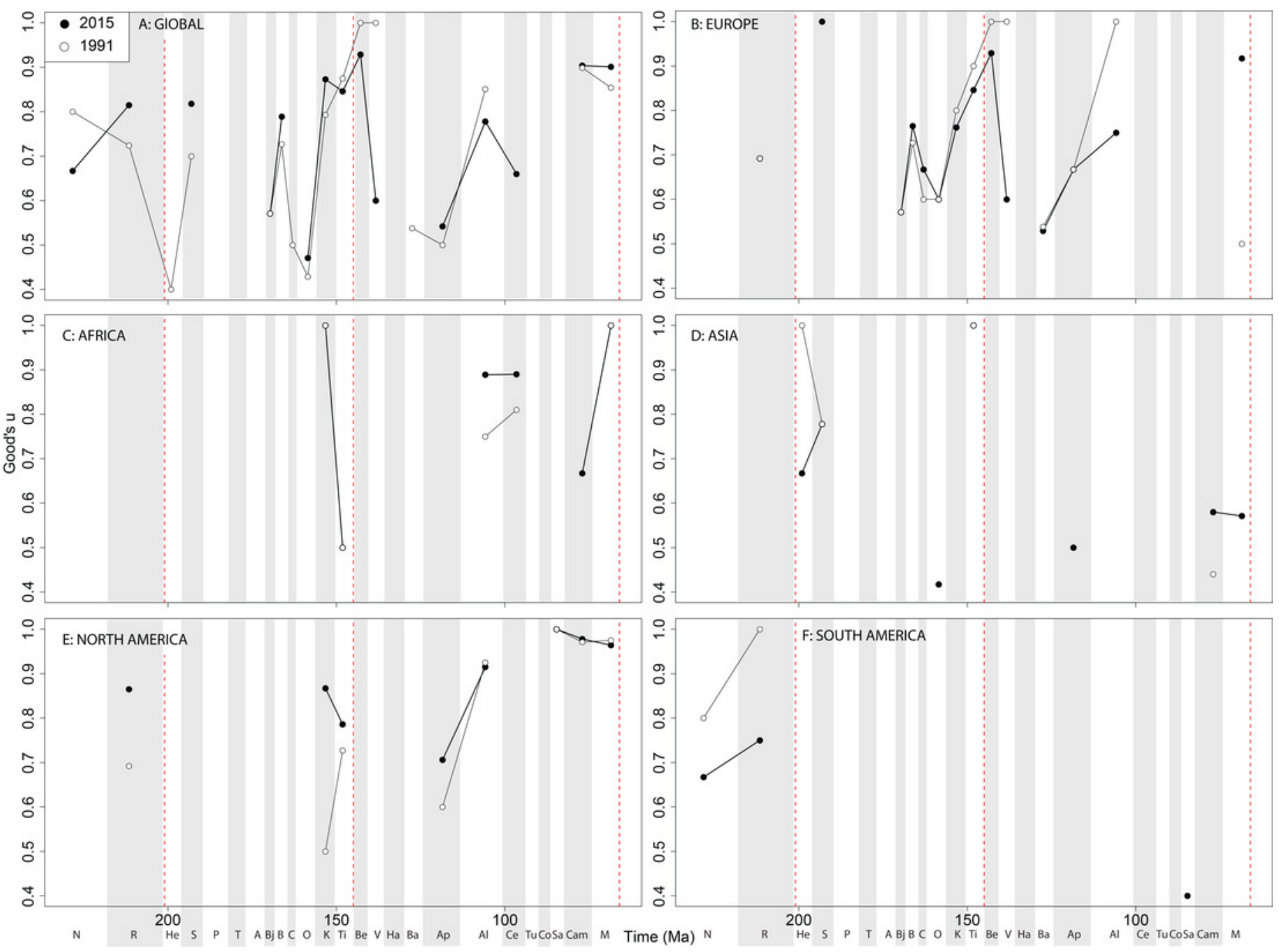


Figure 11

Raw sauropodomorph diversity at A) global and B-F) regional levels (Europe, Africa, Asia, North America, and South America, respectively) based on our published knowledge in 1991 and 2015.

Abbreviations as Figure 4.

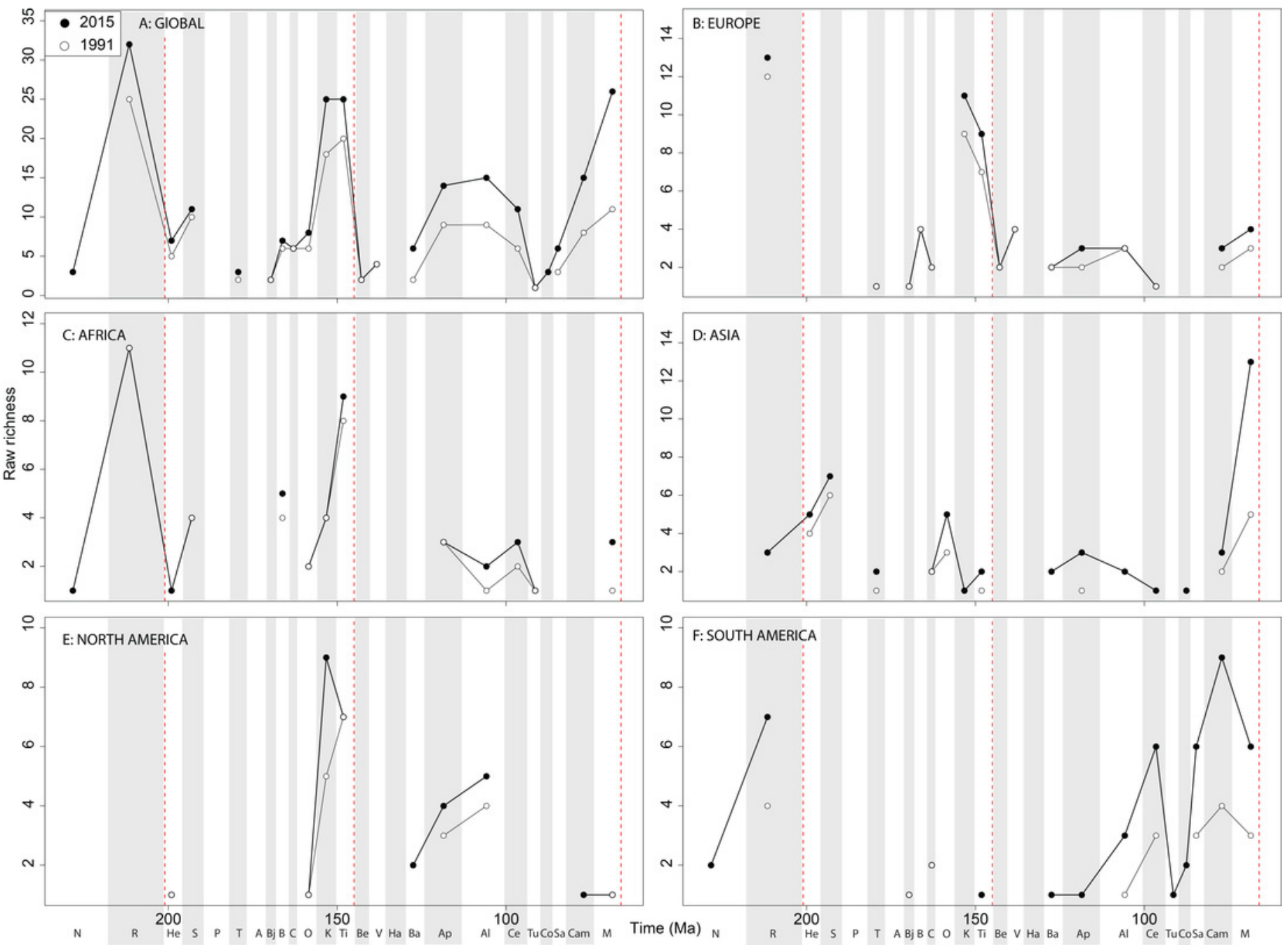


Figure 12

Subsampled sauropodomorph diversity at A) global and B-F) regional levels (Europe, Africa, Asia, North America, and South America, respectively) based on our published knowledge in 1991 and 2015.

Abbreviations as Figure 4.

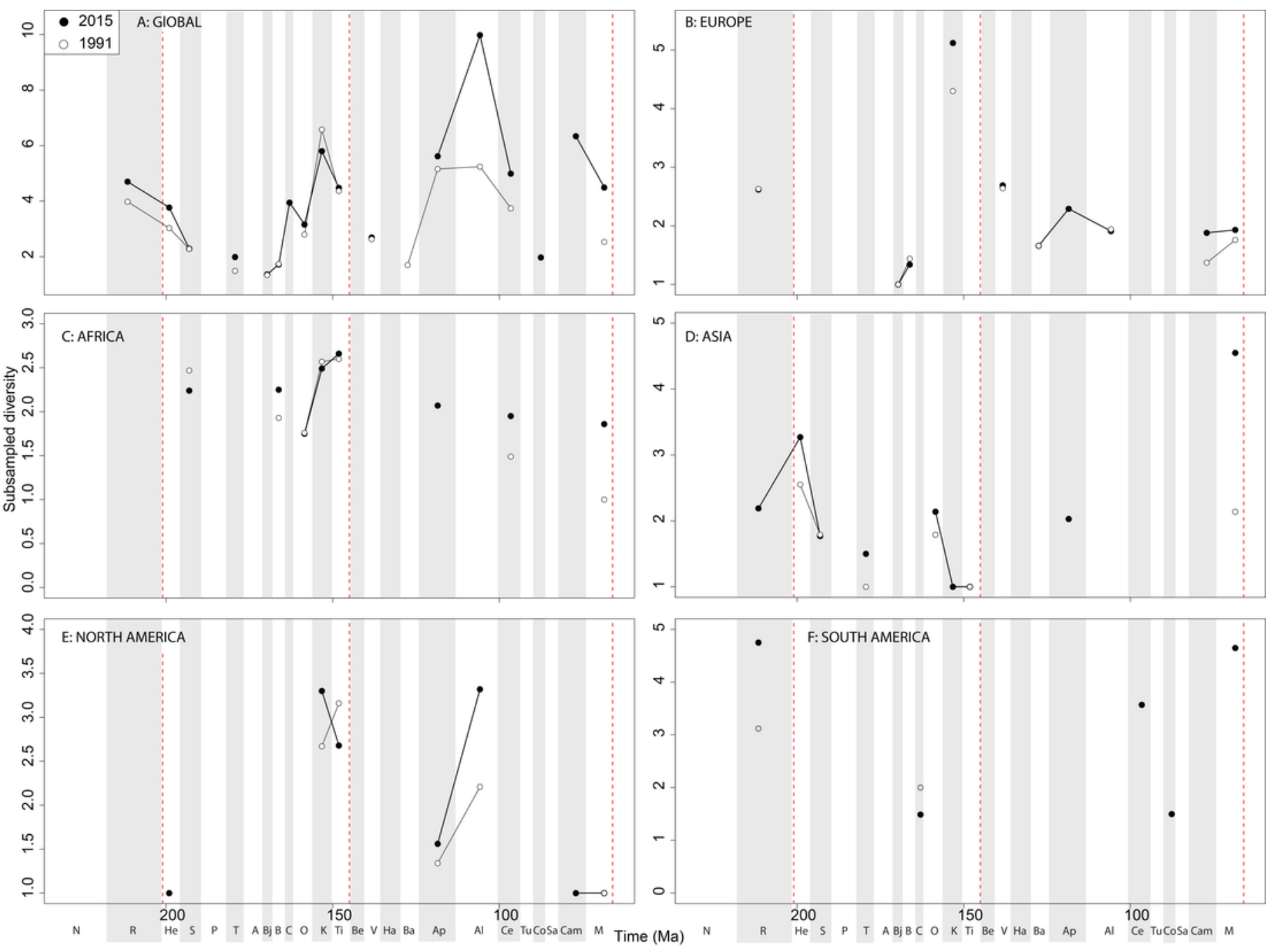


Figure 13

Good's $u$ estimates for sauropodomorphs at a A) global and B-F) regional levels (Europe, Africa, Asia, North America, and South America, respectively) based on our published knowledge in 1991 and 2015.

Abbreviations as Figure 4.
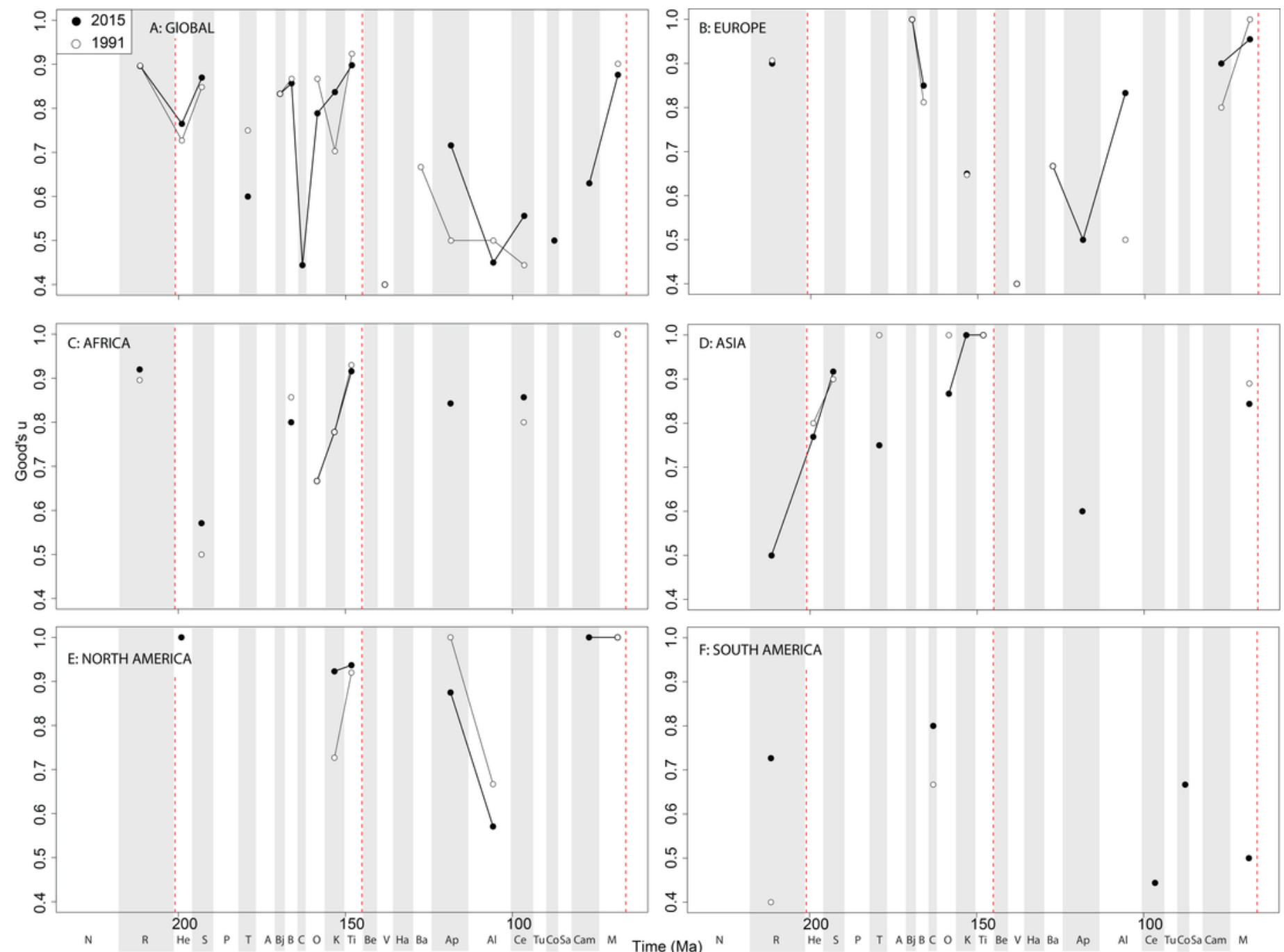
Table $\mathbf{1}$ (on next page)

Ornithischian correlation test results. 
1

\begin{tabular}{|l|l|l|l|l|l|l|l|l|}
\hline \multicolumn{2}{|l|}{ Ornithischians } & $\begin{array}{l}\text { Sea } \\
\text { level }\end{array}$ & & & \multicolumn{2}{l|}{ Palaeotemperature } & \\
\hline & $\begin{array}{l}\text { Shapiro-Wilk } \\
(p)\end{array}$ & $\begin{array}{l}\text { Correlation } \\
\text { test }\end{array}$ & cor & $p$ & $\begin{array}{l}\text { adjusted } \\
p\end{array}$ & cor & $p$ & $\begin{array}{l}\text { adjusted } \\
p\end{array}$ \\
\hline 2015 & 0.003 & Spearman & 0.42 & 0.137 & 0.322 & -0.432 & 0.109 & 0.235 \\
\hline 2013 & 0.002 & Spearman & 0.481 & 0.084 & 0.273 & -0.396 & 0.145 & 0.235 \\
\hline 2011 & 0.002 & Spearman & 0.481 & 0.084 & 0.273 & -0.396 & 0.145 & 0.235 \\
\hline 2009 & 0.002 & Spearman & 0.516 & 0.062 & 0.273 & -0.429 & 0.113 & 0.235 \\
\hline 2007 & 0.001 & Spearman & 0.503 & 0.069 & 0.273 & -0.471 & 0.078 & 0.235 \\
\hline 2005 & $<0.001$ & Spearman & 0.358 & 0.209 & 0.273 & -0.346 & 0.206 & 0.237 \\
\hline 2003 & 0.002 & Spearman & 0.314 & 0.274 & 0.322 & -0.325 & 0.237 & 0.237 \\
\hline 2001 & 0.001 & Spearman & 0.332 & 0.246 & 0.322 & -0.329 & 0.232 & 0.237 \\
\hline 1999 & 0.002 & Spearman & 0.327 & 0.253 & 0.322 & -0.432 & 0.109 & 0.235 \\
\hline 1997 & 0.001 & Spearman & 0.341 & 0.233 & 0.322 & -0.429 & 0.113 & 0.235 \\
\hline 1995 & $<0.001$ & Spearman & 0.258 & 0.394 & 0.394 & -0.367 & 0.197 & 0.237 \\
\hline 1993 & 0.001 & Spearman & 0.413 & 0.185 & 0.322 & -0.495 & 0.089 & 0.235 \\
\hline 1991 & 0.002 & Spearman & 0.329 & 0.297 & 0.322 & -412 & 0.163 & 0.235 \\
\hline
\end{tabular}

2 
Table 2 (on next page)

Sauropodomorph correlation test results. 
1

\begin{tabular}{|l|l|l|l|l|l|l|l|l|}
\hline \multicolumn{2}{|l|}{ Sauropodomorphs } & $\begin{array}{l}\text { Sea } \\
\text { level }\end{array}$ & & & \multicolumn{2}{l|}{ Palaeotemperature } & \\
\hline & $\begin{array}{l}\text { Shapiro-Wilk } \\
(p)\end{array}$ & $\begin{array}{l}\text { Correlation } \\
\text { test }\end{array}$ & cor & $p$ & $\begin{array}{l}\text { adjusted } \\
p\end{array}$ & cor & $p$ & $\begin{array}{l}\text { adjusted } \\
p\end{array}$ \\
\hline 2015 & 0.036 & Spearman & -0.114 & 0.711 & 0.795 & -0.171 & 0.527 & 0.609 \\
\hline 2013 & 0.045 & Spearman & -0.08 & 0.795 & 0.795 & -0.138 & 0.609 & 0.609 \\
\hline 2011 & 0.274 & Pearson & 0.399 & 0.201 & 0.877 & 0.095 & 0.736 & 0.81 \\
\hline 2009 & 0.192 & Pearson & 0.399 & 0.201 & 0.877 & 0.067 & 0.813 & 0.813 \\
\hline 2007 & 0.052 & Pearson & 0.161 & 0.619 & 0.877 & -0.197 & 0.482 & 0.81 \\
\hline 2005 & 0.477 & Pearson & 0.115 & 0.71 & 0.877 & -0.221 & 0.41 & 0.81 \\
\hline 2003 & 0.19 & Pearson & 0.168 & 0.614 & 0.877 & -0.235 & 0.4 & 0.81 \\
\hline 2001 & 0.385 & Pearson & 0.007 & 0.991 & 0.991 & -0.199 & 0.477 & 0.81 \\
\hline 1999 & 0.124 & Pearson & 0.105 & 0.75 & 0.877 & -0.174 & 0.522 & 0.81 \\
\hline 1997 & 0.887 & Pearson & -0.145 & 0.673 & 0.877 & -0.116 & 0.692 & 0.81 \\
\hline 1995 & 0.485 & Pearson & -0.091 & 0.797 & 0.877 & -0.147 & 0.615 & 0.81 \\
\hline 1993 & 0.763 & Pearson & -0.155 & 0.654 & 0.877 & -0.147 & 0.617 & 0.81 \\
\hline 1991 & 0.295 & Pearson & -0.145 & 0.673 & 0.877 & -0.147 & 0.615 & 0.81 \\
\hline
\end{tabular}

2 
Table 3 (on next page)

Theropod correlation tests results. 
1

\begin{tabular}{|l|l|l|l|l|l|l|l|l|}
\hline \multicolumn{2}{|l|}{ Theropods } & $\begin{array}{l}\text { Sea } \\
\text { level }\end{array}$ & & & \multicolumn{2}{l|}{ Palaeotemperature } & \\
\hline & $\begin{array}{l}\text { Shapiro-Wilk } \\
(p)\end{array}$ & $\begin{array}{l}\text { Correlation } \\
\text { test }\end{array}$ & cor & $p$ & $\begin{array}{l}\text { adjusted } \\
p\end{array}$ & cor & $p$ & $\begin{array}{l}\text { adjusted } \\
p\end{array}$ \\
\hline 2015 & 0.036 & Spearman & 0.175 & 0.588 & 0.672 & 0.115 & 0.71 & 0.868 \\
\hline 2013 & 0.098 & Pearson & 0.234 & 0.464 & 0.464 & 0.334 & 0.264 & 0.362 \\
\hline 2011 & 0.027 & Spearman & 0.099 & 0.751 & 0.751 & 0.059 & 0.844 & 0.868 \\
\hline 2009 & 0.032 & Spearman & 0.17 & 0.579 & 0.672 & 0.055 & 0.856 & 0.868 \\
\hline 2007 & 0.029 & Spearman & 0.17 & 0.579 & 0.672 & 0.055 & 0.856 & 0.868 \\
\hline 2005 & 0.072 & Pearson & 0.289 & 0.316 & 0.464 & 0.363 & 0.184 & 0.362 \\
\hline 2003 & 0.027 & Spearman & 0.407 & 0.151 & 0.659 & -0.061 & 0.832 & 0.868 \\
\hline 2001 & 0.006 & Spearman & 0.346 & 0.247 & 0.659 & -0.086 & 0.773 & 0.868 \\
\hline 1999 & 0.028 & Spearman & 0.379 & 0.202 & 0.659 & -0.051 & 0.868 & 0.868 \\
\hline 1997 & 0.193 & Pearson & 0.476 & 0.1 & 0.25 & 0.254 & 0.362 & 0.362 \\
\hline 1995 & 0.107 & Pearson & 0.511 & 0.074 & 0.25 & 0.257 & 0.355 & 0.362 \\
\hline 1993 & 0.101 & Pearson & 0.251 & 0.409 & 0.464 & 0.264 & 0.342 & 0.362 \\
\hline 1991 & 0.013 & Spearman & 0.209 & 0.494 & 0.672 & -0.071 & 0.803 & 0.868 \\
\hline
\end{tabular}

2 


\section{Table 4(on next page)}

Total dinosaur correlation tests results. 
1

\begin{tabular}{|l|l|l|l|l|l|l|l|l|}
\hline \multicolumn{2}{|l|}{ All dinosaurs } & & $\begin{array}{l}\text { Sea } \\
\text { level }\end{array}$ & & & \multicolumn{2}{l|}{ Palaeotemperature } & \\
\hline & $\begin{array}{l}\text { Shapiro-Wilk } \\
(p)\end{array}$ & $\begin{array}{l}\text { Correlation } \\
\text { test }\end{array}$ & cor & $p$ & $\begin{array}{l}\text { adjusted } \\
p\end{array}$ & cor & $p$ & $\begin{array}{l}\text { adjusted } \\
p\end{array}$ \\
\hline 2015 & 0.327 & Pearson & 0.189 & 0.467 & 0.467 & -0.051 & 0.832 & 0.984 \\
\hline 2013 & 0.233 & Pearson & 0.226 & 0.385 & 0.467 & -0.099 & 0.678 & 0.984 \\
\hline 2011 & 0.059 & Pearson & 0.324 & 0.204 & 0.467 & 0.108 & 0.652 & 0.984 \\
\hline 2009 & 0.021 & Spearman & 0.284 & 0.268 & 0.367 & -0.072 & 0.763 & 0.876 \\
\hline 2007 & 0.489 & Pearson & 0.233 & 0.367 & 0.467 & 0.01 & 0.966 & 0.984 \\
\hline 2005 & 0.045 & Spearman & 0.207 & 0.407 & 0.367 & -0.095 & 0.682 & 0.876 \\
\hline 2003 & 0.053 & Pearson & 0.305 & 0.218 & 0.467 & 0.025 & 0.914 & 0.984 \\
\hline 2001 & 0.043 & Spearman & 0.232 & 0.367 & 0.367 & -0.089 & 0.71 & 0.876 \\
\hline 1999 & 0.066 & Pearson & 0.342 & 0.179 & 0.467 & 0.005 & 0.984 & 0.984 \\
\hline 1997 & 0.27 & Pearson & 0.358 & 0.159 & 0.467 & -0.048 & 0.84 & 0.984 \\
\hline 1995 & 0.13 & Pearson & 0.275 & 0.303 & 0.467 & 0.021 & 0.931 & 0.984 \\
\hline 1993 & 0.119 & Pearson & 0.221 & 0.429 & 0.467 & 0.046 & 0.856 & 0.984 \\
\hline 1991 & 0.049 & Spearman & 0.261 & 0.347 & 0.367 & -0.04 & 0.876 & 0.876 \\
\hline
\end{tabular}

2 